\title{
Neurofilament phosphoforms: surrogate markers for axonal injury, degeneration \& loss
}

\author{
Axel Petzold * \\ Department of Neuroimmunology, Institute of Neurology, University College London, \\ Queen Square, London WC1N 3BG, United Kingdom
}

\begin{abstract}
This review on the role of neurofilaments as surrogate markers for axonal degeneration in neurological diseases provides a brief background to protein synthesis, assembly, function and degeneration. Methodological techniques for quantification are described and a protein nomenclature is proposed. The relevance for recognising anti-neurofilament autoantibodies is noted. Pathological implications are discussed in view of immunocytochemical, cellculture and genetic findings. With reference to the present symposium on multiple sclerosis, the current literature on body fluid levels of neurofilaments in demyelinating disease is summarised.
\end{abstract}

Key words: axonal degeneration, blood, cerebrospinal fluid, intermediate filaments, neurofilament, NfH, NfL, NfM, nomenclature, phosphorylation, surrogate marker.

* Dr Axel Petzold, Department of Neuroimmunology, Institute of Neurology, Queen Square, London WC1N 3BG, United Kingdom. Tel.: +44 2078373611 ext. 4204, Fax +44 207837 8553, Email: a.petzold@ion.ucl.ac.uk 


\section{Introduction}

The cytoskeleton of the axon is made of a scaffolding of proteins. Out of these the most important are the neurofilaments. Neurofilaments are an architectonic amazingly stable tube system of about $10 \mathrm{~nm}$ diameter. This size places them intermediate between the smaller microfilaments $(7 \mathrm{~nm})$ and the larger microfilaments $(\approx$ $25 \mathrm{~nm}$ ). Nf are classified as type IV intermediate filaments [1] (Table 1).

Table 1: Classification of intermediate filaments and cell-type specificity. GFAP = glial fibrillary acidic protein. Adapted from [2].

\begin{tabular}{lll}
\hline Class & Identity & Cell-type specificity \\
\hline Type I & Acidic keratins & Epithelial \\
Type II & Neutral \& Basic keratins & Epithelial \\
Type III & GFAP & Astrocyte \\
& Peripherin & Neuronal (peripheral) \\
& Vimetin & Mesenchymal \\
& Desmin & Muscle \\
Type IV & NfL, NfM, NfH & Neuronal \\
& $\alpha-$ Internexin & Neuronal \\
Type V & Lamin A, B, C & Most cells \\
Type VI & Nestin & CNS stem cells \\
\hline
\end{tabular}

To fully appreciate the structural achievement of this protein in cellular architecture one must put the size of neurons and axons into relation. The neuronal cell-bodies (0.01 to $0.05 \mathrm{~mm}$ size) are connected by axons of over $1 \mathrm{~m}$ length (the axonal diameter is 1 to $25 \mu \mathrm{m}$ ). This is a factor of 100,000 difference. How does the neuron achieve to maintain this enormous structure, more importantly, how can the breakdown of the axon be detected and related to disease?

This review focuses on 4 parts; firstly the neurofilament (Nf) subunit synthesis, its assembly into tubular structure and the post-translational modifications with particular reference to phosphorylation; secondly on methodological quantitative techinques; thirdly on clinico-pathological relationships related to Nf disassembly including accumulation, phosphorylation and disease; and finally the potential of Nf to serve as surrogate markers for axonal injury, disintegration and loss with particular reference to multiple sclerosis. 


\section{The Neurofilament triplet protein}

The dominant proteins of the axonal cytoskeleton are Nf. Nf are obligate heteropolymers that are composed of 3 subunits, a light (NfL), a medium (NfM) and a heavy $(\mathrm{NfH})$ chain (these are reviewed in detail by Lee and Cleveland [3]). Nf are CNS cell-type specific proteins (Table 1) and qualify $\mathrm{Nf}$ as potential surrogate markers of damage to neuron and axon.

\subsection{Synthesis and assembly}

NfL The Nf light chain (NfL) is coded on chromosome 8p21 and consists of 543 amino acids. The molecular mass corresponds to $61 \mathrm{kDa}$, but due to phosphorylation and glycosylation, migration in sodium dodecyl sulfate (SDS) polyacrylamide gels (PAGE) is slow, and most authors refer to a molecular mass of $68 \mathrm{kDa}$ as determined in SDS-PAGE.

NfM The Nf medium chain (NfM) is also coded on chromosome 8p21 and consists of 916 amino acids. The molecular mass is calculated as $102.5 \mathrm{kDa}$, and runs at $150 \mathrm{kDa}$ in SDS gels.

NfH The Nf heavy chain (NfH) is coded on chromosome 22q12.2 [4] and consists of 1020 amino acids. The molecular mass of the amino acids corresponds to 111 $\mathrm{kDa}$. Most authors however refer to the molecular mass derived from SDS gels which is also influenced by the charge/weight of bound phosphate and therefore ranges from 190 to $210 \mathrm{kDa}$ for the various phosphoforms.

Structure Each Nf subunit is composed of a highly conserved $\alpha$-helical core region of approximately 310 amino acids. The core region forms a double-stranded coil, flanked by the head ( $\mathrm{N}$-terminus) and the hypervariable tail ( $\mathrm{C}$-terminus) domains [5] (Figure $1 \mathrm{~A}$ ). The reason for the slightly confusing terminology for protein head (carboxy-terminal) and tail (amino-terminal) is historical. The tail of the NfM and NfH subunit protrude from the "head-to-head" assembled polymer. The $\alpha$-helical rod domain is mainly relevant for Nf assembly, whilst the variable head and tail domains are responsible for functional properties such as protein-protein interactions, with the head-domain also contributing to assembly $[6,7,8,9]$. Cross-linking and interaction of the assembled heteropolymers with other cytoskeletal proteins depends mainly upon the $\mathrm{C}$-terminal $\mathrm{NfH}$ tail domain and is of functional importance (Figure $1 \mathrm{~B}$ ). 


\section{(A) Neurofilament Isoforms}

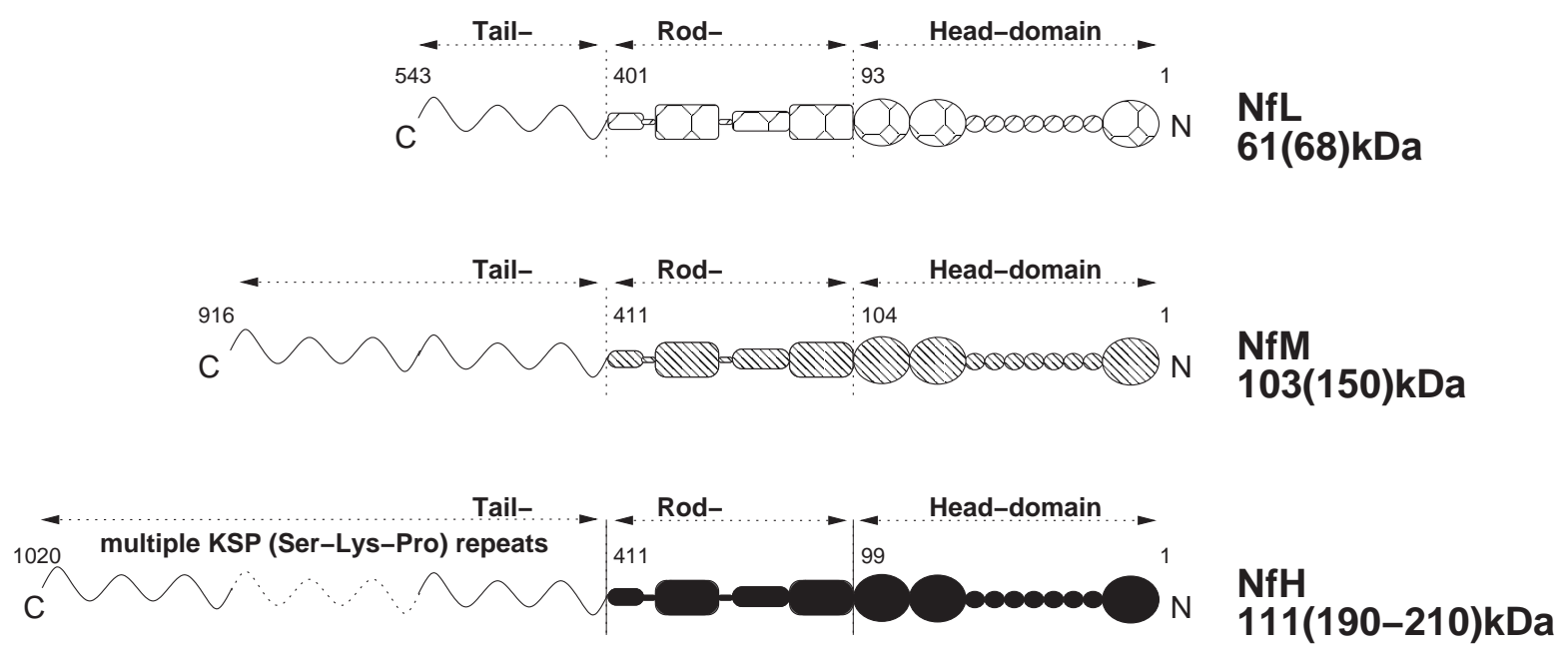

\section{(B) Assembled neurofilament triplet protein}

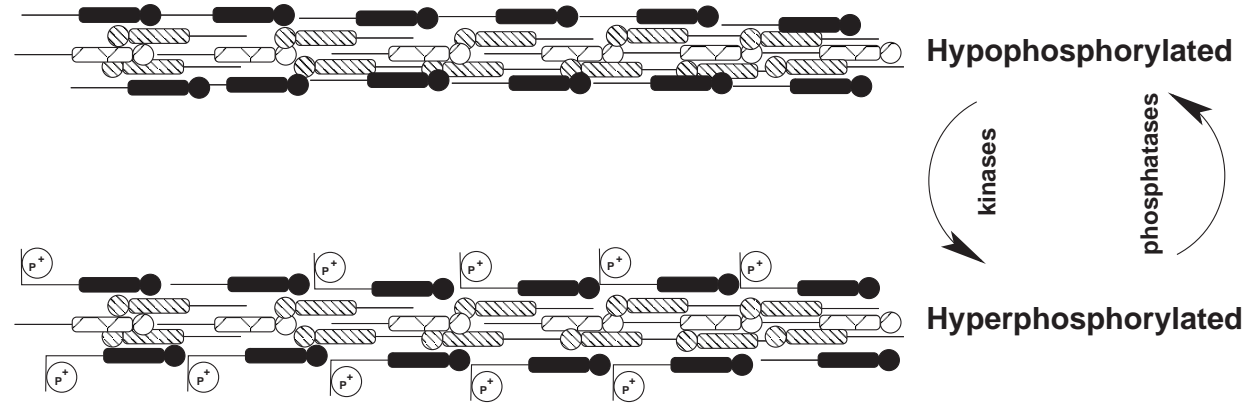

Figure 1. (A) The neurofilament protein subunits. The amino-terminal head domain is of variable length whilst the central rod and carboxy-terminal tail domain remain constant. The calculated molecular weights and the molecular weights as determined by SDS gel electrophoresis (in brackets) are shown.

(B) Functional properties of the neurofilament protein such as cross-linking and protein-protein interactions are controlled locally in the axon by phosphorylation and dephosphorylation.

The formation of the typical IF of $10 \mathrm{~nm}$ diameter is determined by the correct assembly of the NfL, NfM and NfH subunits. The assembly of the three Nf subunits is dependent on the $\mathrm{N}$-terminal head region. NfL is known to polymerise on its own in vitro, while NfM and NfH cannot [10]. However, both NfM and NfH can co-assemble with NfL in vitro [11]. Assembly occurs in 5 stages: polypeptides are wound around each other to form dimers which are sorted in an antiparallel fashion in order to form tetramers, protofilaments and finally IF (Figure 2). The $\alpha$-helical coiled-coil parallel heterodimers contain NfL and either of NfL, NfM or NfH [12]. 


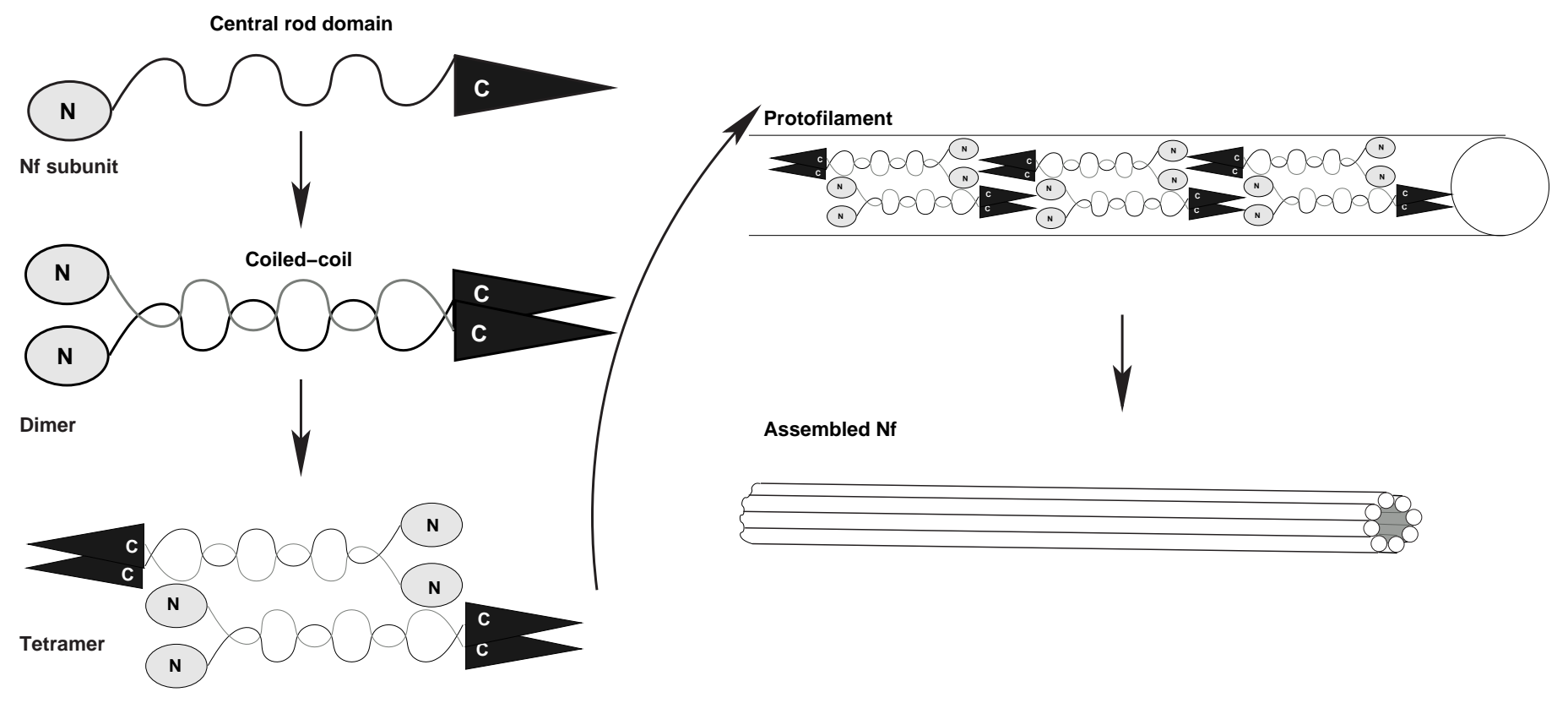

Figure 2. Neurofilament assembly. The central rod domain of the Nf subunits is intertwined in order to form dimers. The dimers are sorted antiparallel and form tetramers. Tetramers combine to form protofilaments, which finally assemble to produce the $10 \mathrm{~nm}$ thick $\mathrm{Nf}$.

Ultrastructural analysis of the NfL assembly process reveal that the lateral association of the protofibrils is promoted by the head-domain and terminated by the tail-domain [13]. In vivo Nfs are obligate heteropolymers [12].

Phosphorylation The neurofilament heavy chain is the most extensively phosphorylated protein of the human brain, and possibly the entire human body. Phosphorylation and dephosphorylation of the neurofilament proteins is a complex process which is predominately regulated within the axonal compartment and targeted on different phosphate acceptor sides in the Nf subunits (Figure 3) [14, 15]. NfM and NfH become highly phosphorylated post-translationally after being transported from the neuronal cell soma in the axon. In vivo phosphorylation of $\mathrm{Nf}$ is slow, orchestrated by a range of enzymes and has recently been reviewed in detail by Grant \& Pant [16]. In brief, enzymatic phosphorylation is predominantly subject to 2 types of kinases: the non-proline directed and the proline directed (i.e. cyclin-kinases and MAP kinases).

Phosphorylation of the $\mathrm{C}$-terminal tail domain is thought to occur at the side arms protruding from the assembled filaments. The $\mathrm{C}$-terminal tail domain consists of 


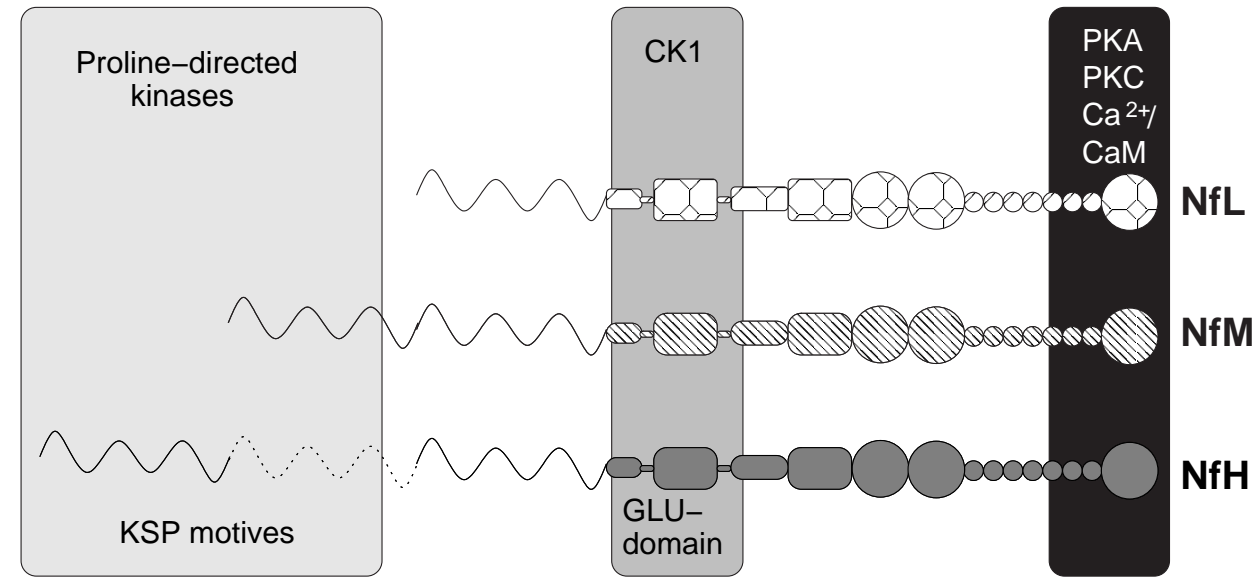

Figure 3. The main phosphorylation sites of different kinases on the three Nf proteins are shown (adapted from [16]).

42 KSP (Lys-Ser-Pro) repeats in humans [17, 18, 19]. Phosphate is coupled with high affinity to serine within the KSP repeats $[18,19]$. An additional phosphate acceptor site with high binding affinity is threonine [16].

The N-terminal domain is phosphorylated by glycogen synthetase kinase-3 [20, $21]$, extracellular signal-regulated kinases $[22,23]$ and cyclin-dependent kinase- 5 [14, 24, 25].

Phosphorylation of the $\mathrm{C}$-terminal domain is regulated by a range of protein kinases $[6,26,27]$.

Glycosylation The NfL (Ser27, Thr21) and NfM (Thr48) head region are posttranslationally modified by adding on $O$-linked $N$-acetylglucosamine moieties [28]. All these locations are essential for in vivo Nf assembly. O-GlcNAc modification has also been reported for the NfH KSP repeats [29], but the precise sites have not yet been identified. It is possible that glycosylation plays a role in Nf trafficking and function.

Terminology Since the use of specific monoclonal antibodies permits us to detect distinct Nf epitopes, the distribution of different $\mathrm{NfH}$ phosphoforms was studied in axonal pathology and in neurodegeneration. It is against the background of this research that Sternberger et al. (1985) proposed the classification of the antibodies, 
recognising these $\mathrm{NfH}$ phosphoforms according to their cellular distribution into 4 groups: Group I antibodies stain cells and structures in the grey matter, Group II antibodies stain for projecting axons, but not for neuronal perikarya, dendrites or proximal axons, Group III antibodies stain for perikarya, dendrites and proximal axons and Group IV antibodies stain for all structures revealed by group II and group III antibodies [30].

However, in the literature reference is commonly made to non-phosphorylated or hypophosphorylated versus hyperphosphorylated or extensively phosphorylated, with phosphorylated being the assumed dominant (normal) NfH phosphoform. The use of mass-spectroscopy permits the identification of the phosphorylation sites within the protein $[18,19]$. This requires labour-intensive pre-analytical purification of Nf sub-units [18] and because of conformational changes correct identification of non-linear epitopes cannot be guaranteed.

The pragmatic approach proposed here is to classify $\mathrm{NfH}$ phosphoforms (NfHp) by naming the detecting antibody in superscript. In other words, if $\mathrm{NfH}$ was detected by the Sternberger monoclonal antibody SMI32 this NfH phosphoform is labelled $\mathrm{NfH}^{\text {SMI32 }}$. Likewise when phosphorylated $\mathrm{NfH}$, was detected by the binding to a phosphorylated epitope recognised by the Sternberger monoclonal antibody $S M I 35$, this is labelled $\mathrm{NfH}^{S M I 35}$. A complete Table of the proposed nomenclature is given in [31]. For each antibody the name of the clone and the source need to be provided. This terminology facilitates comparisons of results between studies and across methods (i.e. immunoblotting, immunocytochemistry and ELISA).

Function About $80 \%$ of axonal Nf are highly phosphorylated and integrated by cross-linking in the axoskeleton, thus constituting the "static pool" [32]. The remaining $20 \%$ of less extensively phosphorylated Nf constitute the so called "dynamic pool" $[33,32]$.

Because phosphorylation alters the charge of the side-arms, it was proposed that one function of phosphorylation is to increase the charge-based repulsion of neighbouring filaments, thereby increasing inter-filament spacing and consequently increasing axonal calibre [34]. The close relation of axonal diameter and conduction velocity $[35,36]$ is of physiological relevance.

However, radial axonal growth does not depend on mechanisms of NfH phosphorylation alone [37] and the original hypothesis, that phosphorylation of NfH sidearms is essential for Nf spacing and radial axonal growth, has been modified in that Nf subunits interact stoichiometrically and NfM is the "preferred" subunit for NfL copolymerisation and main regulator of radial axonal growth [38, 39, 40, 41]. It also seems that NfL and NfM stoichiometrics are more important for axonal growth than NfH phosphorylation. This notion is substantiated by knockout mice experiments [38, 41, 42, 43, 44, 14, 45] (for review see [16, 14]). It was suggested that 
small side-arms extend from non-phosphorylated $\mathrm{NfH}$, but extend much further with phosphorylation and charge-related uncoiling of the KSP repeats [46]. Whilst non-phosphorylated $\mathrm{NfH}$ adhere to microtubules, probably in competition with tau, phosphorylation leads to dissociation from the microtubules [47, 48]. Other IFinteracting proteins are mainly from the plakin family (i.e. the bullous pemphigoid antigen-1 proteins (BPAG1), ACF7, desmoplakin, envoplain and periplakin), the dynein/dynactin complex, myosin Va and probably the $\mathrm{D}(1)$ dopamine receptor (reviewed in [49]). Lee and Cleveland suggested that "the phosphorylation process is ultimately linked to, and may be regulated by, myelination.” [3, p. 204].

The importance of local phosphorylation for regulating Nf assembly is highlighted by the observation that the formation of protofibrils is inhibited if the NfL head domain becomes phosphorylated [50, 51]. In fact phosphorylation of the NfL head domain at Ser55 or the NfM head domain at Ser44 by protein kinase A (PKA) is sufficient to block Nf assembly [6, 27].

The relatively small $(\approx 20 \%)$ "dynamic pool" of non- or hypophosphorylated $\mathrm{NfH}$ $[33,32]$ is involved in ante- and retrograde axonal transport [52].

Axonal transport The initial studies of axonal transport of $\mathrm{Nf}$ using radiographic labelling $[53,54,55]$ suggested a velocity of $\approx 0.25-3 \mathrm{~mm} / \mathrm{d}$ which is slower than any speed produced by known molecular motors [56, 49]. Recent studies using green-fluorescent-protein (GFP)-tagged Nf subunits and real-time confocal microscopy show more accurately that the conventional fast axonal transport also applies to Nf. Peak velocities of 2 /second occur antero- and retrograde and are interrupted by prolonged resting phases resulting in the overall slow transport originally described (reviewed in [57, 49]).

The degree of phosphorylation correlates inversely with the velocity of axonal transport $[58,59,60]$. It has been suggested that this is due to phosphorylation dependent dissociation of $\mathrm{Nf}$ from the kinesin motor [61].

Accumulation of Nf has been shown in a range of diseases. Recent work using GFP-tagged NfM demonstrated in cell-culture (SW13) that treatment with glutamate slows axonal transport and leads to neuronal accumulation of $\mathrm{NfH}^{\text {SMI36 }}$ [62]. This finding supports the concept that glutamate-induced excitotoxicity might contribute to the pathogenic process in some neurodegnerative diseases.

Degradation It is believed that $\mathrm{Nf}$ are broken-up when they arrive at the axon terminus. The breakdown of $\mathrm{Nf}$ depends on protease digestion [63, 64]. Under physiological conditions this is mediated by calmodulin, a $\mathrm{Ca}^{2+}$-dependent protease [65]. Susceptibility of Nf to protease digestion decreases with increase of phosphorylation $[66,67,68]$. This has analytical implications, particularly for NfL 
and the non-phosphorylated forms of NfM and $\mathrm{NfH}$ in protease-rich body fluids such as the cerebrospinal fluid (CSF).

Lee and Cleveland calculated the life-time of $\mathrm{Nf}$ to be around 1-2 years, based on calculating the transit time through the human sciatic nerve at a daily rate of 1$2 \mathrm{~mm} /$ day [3, p. 202]. Because of this long-life Nf are very likely to accumulate damage caused by oxidative stress, inflammation, etc. which could ultimately lead to disturbed filament assembly, accumulation and axonal pathology.

There might be a biological reason why NfL is more susceptible to protease activity then NfH and NfM. The potential of NfL to polymerise on its own could result in protein accumulation, aggregate formation and disease. 


\section{Methodological approaches}

At present three methodological approaches have been undertaken in an attempt to quantify Nf: (1) Western / immunoblotting techniques [67, 69], (2) a dot-blot immunoassay [70] and (3) ELISA techniques [71, 72, 31, 73].

Western \& dot blotting Although of qualitative advantage for distinguishing $\mathrm{NfH}$ phosphoforms and breakdown products, the Western/immuno-blotting techniques have never been adopted on a clinically relevant scale. This is partly due to the semiquantitative and labour intensive nature of the method. It is particularly difficult to overcome the densitometric limitations of highly sensitive methods such as chemiluminescence because of the high gamma of photographic paper which results in a steep standard curve with a very small linear range. New charged-double device (CDD) cameras which enable one to obtain serial images could help to overcome this problem [74]. The trouble with a dot-blot approach is specificity which impacts on CV and reproducibility. In contrast the ELISA approach provides the highest analytical accuracy and is ideal for a high throughput of samples.

ELISA Two Nf subunits have been investigated in human body fluids using ELISA: NfL [71, 73] and NfH [72, 31]. The Lars Rosengren group concentrated for over 10 years on NfL with good reason: this Nf protein is considered to represent the most abundant subunit, hence the term "backbone" of the Nf polymer. It also is the smallest and most soluble subunit. These requirements would make it an ideal candidate for a surrogate marker if it were not for some concerns about its susceptibility to proteases, particularly in the protease-rich CSF. Thus rigorous sample handling is recommended (i.e. snap-freezing of the CSF at the bedside).

Because of the associated logistical problems our group has concentrated on $\mathrm{NfH}$, which in its phosphorylated state is more resistant to proteases [66, 31, 67, 68]. Additionally $\mathrm{NfH}$ phosphorylation is of functional importance in axonal pathology. Information on the quantitative relationship of $\mathrm{NfH}$ phosphoforms might provide further insight in the dynamics of axonal injury and thus contribute to our understanding of neurodegenerative diseases.

Autoantibodies It is of note that the presence of neurofilament auto-antibodies has been observed by several groups $[75,76,77,78,79]$, mainly in chronic diseases. Because Nf auto-antibodies potentially decrease body fluid antigen levels, they could influence the quantification of Nf by ELISA or other methods and should ideally be measured in order to allow for a balanced interpretation of the data. 


\title{
4 Axonal pathology
}

$\mathrm{Nf}$ subunits are actively involved in the pathogenesis of axonal dysfunction and degeneration both as causative agents for disease and as markers for disease progression.

\subsection{Neurology of $N f$}

It has been suggested the neurology of $\mathrm{Nf}$ be classified into disorders of $\mathrm{Nf}$ synthesis, phosphorylation, distribution by axonal transport, and their breakdown [80].

The accumulation of $\mathrm{Nf}$ proteins has been observed in amyotrophic lateral sclerosis (ALS, synonymous with motor neuron disease) [81], spinal muscular atrophy [82], Parkinson's disease (PD), some dementias (as a component of Lewy bodies together with $\alpha$-synuclein), Alzheimer's disease (AD), progressive supranuclear palsy (PSP), diabetic polyneuropathy and giant axonal neuropathy [83].

Multiple sclerosis In MS, axonal injury has been related to increased staining by $\mathrm{NfH}^{\text {SMI32 }}$ [84, Figure $\left.8 \mathrm{~B}\right]$. $\mathrm{NfH}^{\text {SMI32 }}$ was particularly abundant in axonal ovoids which indicate the site of axonal transection. With regard to cortical lesions Bö provided evidence for axonal loss by demonstrating the frequent occurrence of ovoids. Interestingly, and in contrast to the finding by Trapp et al. [84], the intensity of staining of non-phosphorylated $\mathrm{NfH}\left(\mathrm{NfH}^{\text {SMI32 }}\right)$ was reduced in most cortical regions of axons with myelin loss, whilst staining for phosphorylated $\mathrm{NfH}\left(\mathrm{NfH}^{\text {SMI34 }}\right.$ ) increased [85]. One might speculate that this difference in patterns of NfH phosphorylation reflects differences in patterns of damage, i.e. Wallerian degeneration in white matter pathology versus dying back neuropathy in grey matter pathology.

\begin{abstract}
Alzheimer's disease In $\mathrm{AD}$, increased staining for phosphorylated $\mathrm{NfH}$ is evident in the proximal axon and the perikaryon [30, 86, 87, 88]. The NfH phosphorylation in axons elongating from $\mathrm{AD}$ plaques is particularly intriguing and has been interpreted as evidence of early axonal injury caused by toxic properties of the plaque $[67,87,88]$. Others provided evidence that $\mathrm{NfH}^{\text {SMI32 }}$ positive neurons are selectively lost in AD [89, 90, 91]. This finding was supported by demonstrating kainate-dependent hyper-vulnerability of $\mathrm{NfH}^{\text {SMI32 }}$ positive neurons [91].
\end{abstract}

Amyotrophic lateral sclerosis In ALS, increased staining for phosphorylated $\mathrm{NfH}$ (i.e. $\mathrm{NfH}^{S M I 34}, \mathrm{NfH}^{S M I 35}$ ) has been shown in axons and the neuronal cell 
bodies. There is evidence for accumulation of phosphorylated $\mathrm{NfH}$ in the degenerating motor neurons $[81,92]$. However, $\mathrm{Nf}$ dephosphorylation has also been reported to precede excitotoxicity in a spinal cord cell culture model of ALS [93, 94]. Extending this work, the same group has recently reported an increase in staining for $\mathrm{NfH}^{\text {SMI32 }}$ of cultured spinal cord neurons after exposure to CSF from patients with ALS [95]. Interestingly 3 of the 6 control CSF samples were from patients with MS, but the breakdown of the individual data was not published [95]. The implications of $\mathrm{Nf}$ aggregation, mainly in the neuronal cell body, is a prominent feature of ALS and has been studied in depth mainly by Jean Pierre Julien's group using the gain of function SOD- mouse (for review see [96, 97, 98, 99]). It seems that somal accumulation is preceded by disruption of axonal $\mathrm{Nf}$ transport due to stoichiochemical imbalance of the Nf subunits. However the pathological implications of somal accumulations are not entirely clear and the same group holds a patent protecting one approach to using $\mathrm{Nf}$ phosphorylation as a neuroprotective strategy.

Cerebrovascular pathology In stroke, Hedreen and colleagues demonstrated accumulation of phosphorylated $\mathrm{NfH}\left(\mathrm{NfH}^{\text {SMI35 }}, \mathrm{NfH}^{\text {SMI34 }}, \mathrm{NfH}^{\text {SMI31 }}\right)$ in neuronal cell-bodies and dendrites which were likely to have suffered from axonal disconnection in stroke (i.e. in the thalamus and cerebral cortex) [100]. This phenomenon was observed up to 2 months after a stroke. The authors suggested impaired axonal transport as the pathological correlate. In a recent study on intracranial and subdural haemorrhage we found an increase of the phosphorylated $\left(\mathrm{NfH}^{S M I 34}, \mathrm{NfH}^{S M I 35}\right.$, $\mathrm{NfH}^{S M I 310}$ ) but not of the non-phosphorylated $\left(\mathrm{NfH}^{\text {SMI310 }}\right)$ protein [101].

Glaucoma The monkey model of glaucoma is the only other condition apart from MS [84] where, to the best of my knowledge, increased staining of nonphosphorylated $\mathrm{NfH}$ has been related positively to axonal loss [102]. Kashiwagi and colleagues stained the optic nerves for SIGMA NF-200 ( $\left.\mathrm{NfH}^{\text {NE14 }}\right)$ and $\mathrm{NfH}^{\text {SMI31 }}$. The $\frac{N f H^{S M 131}}{N f H^{N E 14}}$ ratio was used to calculate the phosphorylation status (a high ratio indicating a high degree of phosphorylation). In the glaucomatous eye there was a decrease in staining for $\mathrm{NfH}^{S M I 31}$ in the retina, the optic disc and optic nerve reaching as far back as the optic chiasm. There was a 4-fold difference in the degree of phosphorylation in all but the nasal retina, ranging from $\approx 21-53 \%$ in the glaucomatous to $85-97 \%$ in the control eyes. This semiquantitative finding is supported by Western blot analysis showing a stronger band for $\mathrm{NfH}^{\text {SMI32 }}$ in tissue homogenate from the glaucomatous eye. The authors speculate that this might be related to disturbance of axonal transport, a well known phenomenon in glaucoma, but leave it open as to whether $\mathrm{NfH}$ dephosphorylation is "the chicken or the egg" in this process [102]. 


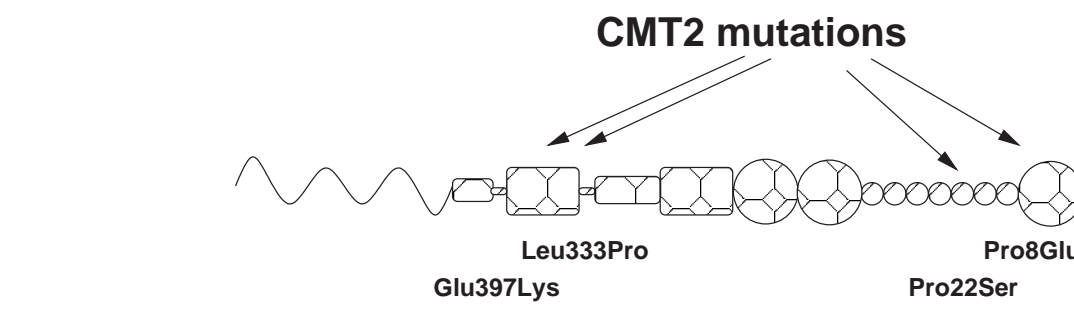

NfL

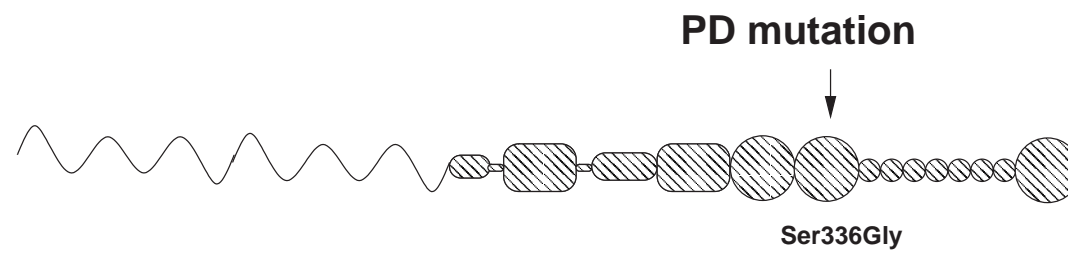

NfM

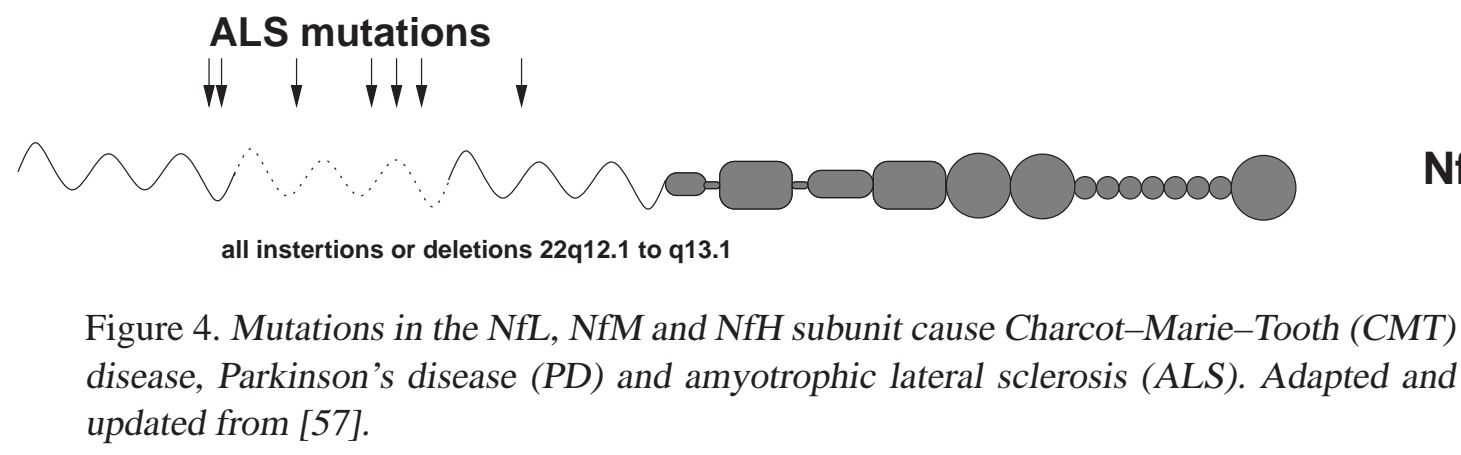

Charcot-Marie Tooth disease CMT is an inherited neuropathy comprising a range of genetic classifications (for review see [103, 104]). The axonal form (CMT2E) has been associated with mutations in the rod domain of the NfL subunit $[105,106$, 107, 108, 109] (Figure 4). Mutation close to the NfL rod-domain causes an increase of neuronal NF-L due to impaired Nf assembly [110]. Whether the problem is primarily due to increased axonal vulnerability caused by impaired axonal transport [110] or to cytoskeletal instability remains to be clarified.

Parkinson's disease In PD a single case report with a point mutation in the rod domain of NfM has been reported [111]. However, three unaffected members of this family also carried the same mutation. The link between genotype and phenotype remains to be proven.

Diabetic neuropathy This is mostly of the symmetrical sensory distal axonal type. An increase of Nf phosphorylation has been observed in humans [112] and in the lumbar dorsal root ganglia of rats with streptozocin-induced diabetes [113]. It has been suggested that activation of c-Jun NH2-terminal kinase (JNK) plays a role in this process. 
Giant axonal neuropathy The hallmark of giant axonal neuropathy (GAN) is the segmental axonal accumulation of $\mathrm{Nf}$ [83]. This is due to multiple mutations on chromosome 16q24.1 encoding for gigaxonin [114]. Gigaxonin is a 597-amino acid BTB (Broad-Complex, Tramtrack and Bric-a-brac)/Kelch protein. It has been suggested that gigaxonin serves as an IF association protein [80]. Gigaxonin disruption leads to $\mathrm{Nf}$ disorganisation and massive multifocal $\mathrm{Nf}$ accumulation.

Miscellaneous conditions Giant axonal swellings have also been observed in iminodipropionitrile (IDPM) and 2,5-Hexanedione (glue-sniffing) neuropathy [80]. Others observed increased $\mathrm{NfH}$ phosphorylation in opiate addiction in humans [115] and mice [116].

\subsection{NfH phosphorylation status and disease}

In order to obtain more information on the $\mathrm{NfH}$ phosphorylation status several authors stained for phosphorylated (e.g. $\mathrm{NfH}^{\text {SMI34 }}$ ) and non-phosphorylated (e.g. $\mathrm{NfH}^{\text {SMI32 }}$ ) pre- and post-enzymatic dephosphorylation with alkaline phosphatase (ALP) $[117,67,30,118,119,87,88,119,86]$. The results of these experiments have been summarised for the non-phosphorylated NfH SMI epitopes in Table $2 \&$ 3. For each $\mathrm{NfH}$ phosphoform the antibody source and main effects as observed by immunocytochemistry were summarised with regard to ALP-treated versus nontreated tissue sections. Because the applied method of dephosphorylation varied considerably (e.g. incubation times from 2.5 to 18 hours), the protocol is referred to in the footnotes of Tables 2 and 4. It is worthwhile remembering that ALP used in all of these experiments was not $100 \%$ pure and a certain degree of NfH proteolysis due to contamination with proteases is possible, particular for the longer incubation periods (i.e. $18 \mathrm{~h}$ at $32^{\circ} \mathrm{C}$ ).

The results are contradictory, on one side non-phosphorylated $\mathrm{NfH}$ (i.e. $\mathrm{NfH}^{\text {SMI32 }}$ ) seems to indicate either vulnerable neurons or injured axons in diseases such as MS, glaucoma, ALS and AD [84, 93, 94, 95, 89, 90, 91]. On the other side phosphorylated $\mathrm{NfH}$ (i.e. $\mathrm{NfH}^{S M I 34}$ or $\mathrm{NfH}^{S M I 35}$ ) is related to axons injured by plaque toxicity, to neurofibrillary tangles (NFT) [120, 87, 88, 30, 86], an axon-proximal finding in dementia $[119,92,81,30,87,88,86]$, indicative of axonal damage in stroke [100], a hallmark of GAN [83].

The puzzle of whether increased or decreased Nf phosphorylation indicates axonal injury is unsolved. The field is open to speculation on disease chronicity, impairment of axonal transport, enzymatic imbalance, etc. 
Table 2: Non-phosphorylated Nf stained in immunocytochemistry by the SMI clones. Characterisation of the antibody staining pattern in untreated and ALP treated sections. N.D. = not determined, $N / A=$ not available/ data was not shown, GM = grey matter, $W M=$ white matter, $+=$ positive,$-=$ negative,$\downarrow$ less intense after ALP treatment.

\begin{tabular}{|c|c|c|c|}
\hline Antibody & Model & Not treated & ALP Treated \\
\hline $\mathrm{NfH}^{\text {SMI32 }}$ & ctrl & thick axons $(+)[67,117,118]$ & thick axons $(+)^{*}$ \\
\hline $\mathrm{NfH}^{\text {SMI32 }}$ & ctrl & neuron/dendrites $(++)[67,117,118]$ & neuron/dendrites $(++)$ \\
\hline $\mathrm{NfH}^{S M I 32}$ & cell culture & vulnerable GABAergic axons (+++) [91] & N.D. \\
\hline $\mathrm{NfH}^{\text {SMI32 }}$ & MS & demyelinated axons $(+++)[84]$ & N/A \\
\hline $\mathrm{NfH}^{S M I 32}$ & MS & axonal ovoids $(+++)[84]$ & N/A \\
\hline $\mathrm{NfH}^{S M I 32}$ & $\mathrm{AD}$ & plaques $(+)[87]$ & plaques +++ \\
\hline $\mathrm{NfH}^{\text {SMI32 }}$ & $\mathrm{AD}$ & dystrophic neurons $(+)[88]$ & $++{ }^{\dagger}$ \\
\hline $\mathrm{NfH}^{\text {SMI33 }}$ & $\mathrm{AD}$ & data not shown $[88]$ & N/A \\
\hline $\mathrm{NfH}^{S M I 33}$ & $\mathrm{AD}$ & $\mathrm{GM}++: \mathrm{AD}=\mathrm{CTRL}[120]$ & N.D. \\
\hline $\mathrm{NfH}^{S M I 33}$ & $\mathrm{AD}$ & $\mathrm{WM}+: \mathrm{AD}=\mathrm{CTRL}[120]$ & N.D. \\
\hline $\mathrm{NfH}^{S M I 33}$ & $\mathrm{AD}$ & pyramidal neurons, no NFT +++: AD $<<<$ CTRL [120] & N.D. \\
\hline $\mathrm{NfH}^{S M I 33}$ & $\mathrm{AD}$ & pyramidal neurons, with NFT +: AD = CTRL [120] & N.D. \\
\hline $\mathrm{NfH}^{\text {SMI33 }}$ & ALS & Spine: $\operatorname{ctrl}>$ ALS [119] & staining $\downarrow \downarrow \ddagger$ \\
\hline
\end{tabular}

* Alkaline phosphatase treatment: $43 \mu \mathrm{L}$ calf intestinal alkaline phosphatase (type VII, Sigma) per $\mathrm{mL}$ in $0.1 \mathrm{M}$ Tris- $\mathrm{HCl}, \mathrm{pH} 8.0,0.01 \mathrm{M}$ phenyl-methylsulfonyl fluoride, at $32^{\circ} \mathrm{C}$ for 18 hours.

$\dagger$ Alkaline phosphatase treatment: $400 \mu \mathrm{g} / \mathrm{mL}$ calf intestinal alkaline phosphatase (type VII, Sigma) in $0.1 \mathrm{M}$ Tris-HCl, pH 8.0, at $37^{\circ} \mathrm{C}$ for $1.5-2$ hours.

$\ddagger$ Alkaline phosphatase treatment: $400 \mu \mathrm{g} / \mathrm{mL}$ calf intestinal alkaline phosphatase (type VII, Sigma) in $0.1 \mathrm{M}$ Tris- $\mathrm{HCl}, 0.01 \mathrm{M}$ phenylmethylsulfonylfluoride, $\mathrm{pH} 8.0$, at $32^{\circ} \mathrm{C}$ for 2.5 hours. Similar results were found for pretreatment with trypsin (GIBCO), $400 \mu \mathrm{g} / \mathrm{mL}$ in $0.05 \mathrm{M}$ Tris-HCL, $0.3 \mathrm{M}$ sodium chloride, $0.02 \mathrm{M} \mathrm{CaCl}, \mathrm{pH} 7.6,37^{\circ} \mathrm{C}$ for 10 minutes. 
Table 3: Phosphorylated Nf stained in immunocytochemistry by SMI clones. Characterisation of the antibody staining pattern in untreated and ALP treated sections.

\begin{tabular}{|c|c|c|c|}
\hline Antibody & Model & Not treated & ALP Treated \\
\hline $\mathrm{NfH}^{S M I 31}$ & ALS & Brain: ctrl > ALS [119] & staining $\downarrow \downarrow$ \\
\hline $\mathrm{NfH}^{S M I 31}$ & $\mathrm{AD}$ & $\mathrm{GM}+: \mathrm{AD}=\mathrm{CTRL}[120]$ & N.D. \\
\hline $\mathrm{NfH}^{S M I 31}$ & $\mathrm{AD}$ & $\mathrm{WM}+++: \mathrm{AD}=\mathrm{CTRL}[120]$ & N.D. \\
\hline $\mathrm{NfH}^{S M I 31}$ & $\mathrm{AD}$ & pyramidal neurons, no NFT —: AD = CTRL [120] & N.D. \\
\hline $\mathrm{NfH}^{S M I 31}$ & $\mathrm{AD}$ & pyramidal neurons, with NFT —: AD = CTRL [120] & N.D. \\
\hline $\mathrm{NfH}^{S M I 31}$ & $\mathrm{AD}$ & data not shown [87] & N/A \\
\hline $\mathrm{NfH}^{S M I 31}$ & $\mathrm{AD}$ & $(+)[88]$ & N/A \\
\hline \multirow[t]{3}{*}{$\mathrm{NfH}^{S M I 34}$} & ctrl & thick axons $(+++)[67,117,118]$ & staining abolished \\
\hline & & thin axons $(++)[67,117,118]$ & staining abolished \\
\hline & & basket cell dendrites $(+)$ & staining abolished \\
\hline $\mathrm{NfH}^{S M I 34}$ & $\mathrm{AD}$ & $\mathrm{GM} \pm: \mathrm{AD}=\mathrm{CTRL}[120]$ & N.D. \\
\hline $\mathrm{NfH}^{S M I 34}$ & $\mathrm{AD}$ & $\mathrm{WM} \pm: \mathrm{AD}=\mathrm{CTRL}[120]$ & N.D. \\
\hline $\mathrm{NfH}^{S M I 34}$ & $\mathrm{AD}$ & pyramidal neurons, no NFT —: AD = CTRL [120] & N.D. \\
\hline $\mathrm{NfH}^{S M I 34}$ & $\mathrm{AD}$ & pyramidal neurons, with NFT +++: AD $>>>$ CTRL [120] & N.D. \\
\hline $\mathrm{NfH}^{S M I 34}$ & ALS & Spine: $\mathrm{ctrl}=$ ALS [119] & staining $\downarrow \downarrow$ \\
\hline $\mathrm{NfH}^{S M I 34}$ & ALS & Brain: ctrl $>>$ ALS [119] & staining $\downarrow \downarrow$ \\
\hline $\mathrm{NfH}^{S M I 35}$ & ALS & Brain: ALS $>>>$ CTRL [119] & staining $\downarrow \downarrow$ \\
\hline $\mathrm{NfH}^{S M I 35}$ & ctrl & thick axons $(++)[67,117,118]$ & staining reduced \\
\hline $\mathrm{NfH}^{S M I 35}$ & ctrl & thin axons $(+++)[67,117,118]$ & staining reduced \\
\hline $\mathrm{NfH}^{S M I 35}$ & ctrl & neuron/dendrites $(+/-)$ & staining abolished \\
\hline $\mathrm{NfH}^{S M I 35}$ & $\mathrm{AD}$ & $\mathrm{GM}+: \mathrm{AD}=\mathrm{CTRL}[120]$ & N.D. \\
\hline $\mathrm{NfH}^{S M I 35}$ & $\mathrm{AD}$ & $\mathrm{WM}++: \mathrm{AD}<<\mathrm{CTRL}[120]$ & N.D. \\
\hline $\mathrm{NfH}^{S M I 35}$ & $\mathrm{AD}$ & pyramidal neurons, no NFT —: AD = CTRL [120] & N.D. \\
\hline $\mathrm{NfH}^{S M I 35}$ & $\mathrm{AD}$ & pyramidal neurons, with NFT ++: AD $>>$ CTRL [120] & N.D. \\
\hline $\mathrm{NfH}^{S M I 310}$ & ALS & inconsistent results [119] & staining $\downarrow \downarrow$ \\
\hline
\end{tabular}


N.D. 
Table 4: Neurofilament antibodies other than then the SMI clones used for immunocytochemistry. N4142 was a rabbit polyclonal anti-NfH from Sigma.

\begin{tabular}{|c|c|c|c|}
\hline Antibody & Model & Not treated & ALP Treated \\
\hline $\mathrm{NfH}^{N 4142}$ & $\mathrm{AD}$ & data not shown [87] & N/A \\
\hline $\mathrm{NfH}^{R T 97}[121]$ & $\mathrm{AD}$ & Cerebellum $+[122]$ & staining $\downarrow *$ \\
\hline $\mathrm{NfH}^{R T 97}[121]$ & $\mathrm{AD}$ & Hippocampus $+[122]$ & staining $\downarrow \downarrow$ \\
\hline $\mathrm{NfH}^{R T 97}[121]$ & $\mathrm{AD}$ & Hippocampus NFT + [122] & staining $\downarrow$ \\
\hline $\mathrm{NfH}^{R T 97}[121]$ & nerve injury & $+++:$ neurons with crushed nerves $>>>$ CTRL [123] & N.D. \\
\hline $\mathrm{NfH}^{B F 10}[121]$ & $\mathrm{AD}$ & Cerebellum + [122] & staining $\downarrow$ \\
\hline $\mathrm{NfH}^{B F 10}[121]$ & $\mathrm{AD}$ & Hippocampus + [122] & staining $\downarrow$ \\
\hline $\mathrm{NfH}^{B F 10}[121]$ & $\mathrm{AD}$ & Hippocampus NFT + [122] & + \\
\hline $\mathrm{NfH}^{B F 147}[121]$ & $\mathrm{AD}$ & Cerebellum $+[122]$ & staining $\downarrow$ \\
\hline $\mathrm{NfH}^{B F 147}[121]$ & $\mathrm{AD}$ & Hippocampus $+[122]$ & staining $\downarrow \downarrow$ \\
\hline $\mathrm{NfH}^{B F 147}[121]$ & $\mathrm{AD}$ & Hippocampus NFT — [122] & staining - \\
\hline $\mathrm{NfH}^{1 D}[124]$ & CJD & swollen neurons: + [125] & $-\dagger$ \\
\hline $\mathrm{NfH}-\mathrm{P}$ & WHD & early damage in LMN ++ [126] & N.D. \\
\hline $\mathrm{NfH}^{\text {mab1.1.1 }}[127]$ & $\mathrm{AD}$ & $\mathrm{AD}+, \mathrm{CTRL}:-[128]$ & N.D. \\
\hline $\mathrm{NfH}^{M A B 147}[121]$ & tractotomy & affected neurons: + [129] & N.D. \\
\hline
\end{tabular}

Anti-Nf auto-antibodies The presence of human anti-Nf auto-antibodies has been studied in a range of diseases. This might be of particular importance in

* Alkaline phosphatase treatment: $100 \mu \mathrm{L}$ calf intestinal alkaline phosphatase (Supplier not given) in $0.1 \mathrm{M}$ Tris- $\mathrm{HCl}, \mathrm{pH} 8.0$, at $37^{\circ} \mathrm{C}$ for 2.5 hours.

$\dagger$ Alkaline phosphatase treatment: $20 \mathrm{IU} / \mathrm{mL}$ alkaline phosphatase (Supplier not given) in $0.1 \mathrm{M}$ Tris- $\mathrm{HCl}, 5 \mathrm{mM}$ phenylmethylsulfonyl fluoride $\mathrm{pH}$ 8.0, at room temperature for 24 hours. 


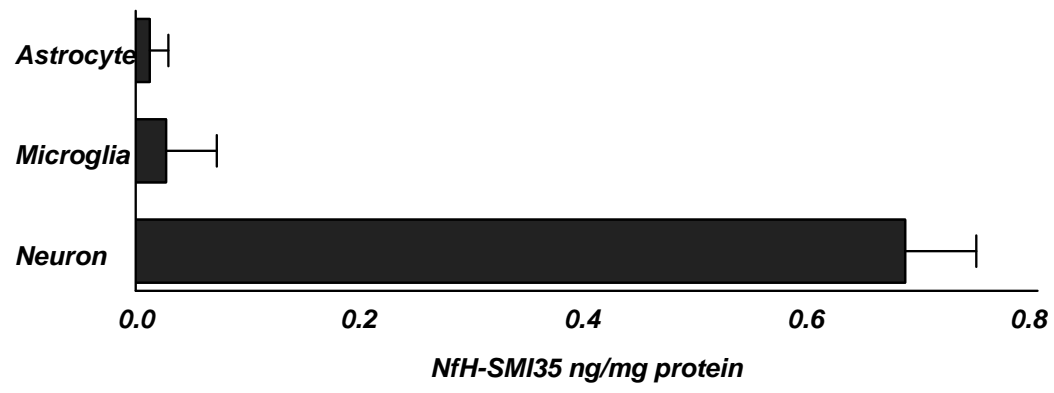

Figure 5. Levels of $\mathrm{NfH}^{S M I 35} \mathrm{ng} / \mathrm{mg}$ protein in homogenised neurons, astrocytes and microglia (mean $\pm S D$ ). Adapted with permission from [31].

chronic diseases where accumulation of axonal degeneration leads to continuous Nf release and consequently to stimulation of the humoral immune-system. These may interfere with ELISA.

$\mathrm{Nf}$-autoantibodies have been found in multiple sclerosis [75, 76], as a cause for conduction block in neuropathy with monoclonal gammopathy of undetermined significance [77], in patients with rheumatoid arthritis and neuropathy [78] and in ALS [79]. It is beyond the scope of this manuscript to review the literature of antiNf autoantibodies other than reminding readers of their existence.

\subsection{Cross-validation of quantitative approaches estimating axonal loss}

For a Nf ELISA to be used for estimating axonal degeneration and loss in vivo, two experiments need to be carried out: firstly it must be shown that Nf is present exclusively in the neuro-axonal compartment, thus $\mathrm{Nf}$ cannot be released from other cell-types (cell-type specificity); secondly a correlation should exist between tissue axonal count and Nf levels in tissue homogenate.

Cell-type specificity was demonstrated for $\mathrm{NfH}^{S M I 35}$ using primary neuronal, astrocytic and microglial cell-cultures (Figure 5) [31]. However after publishing the method I noticed a report on the presence of NfH in T-lymphocytes [130] and embryonic heart muscle [131]. Thus proof that all body fluid $\mathrm{NfH}^{S M I 35}$ is truly due to axonal disintegration remains to be obtained. Whilst contamination might be negligible for the CSF this is an important experiment to be carried out for interpretation of blood levels of any of the Nf subunits.

A qualitative rather than quantitative relationship between axonal loss in spinal 
(A)

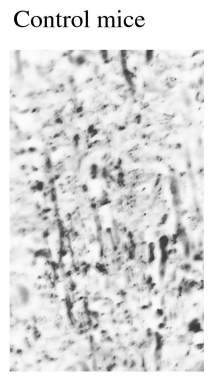

CREAE mice

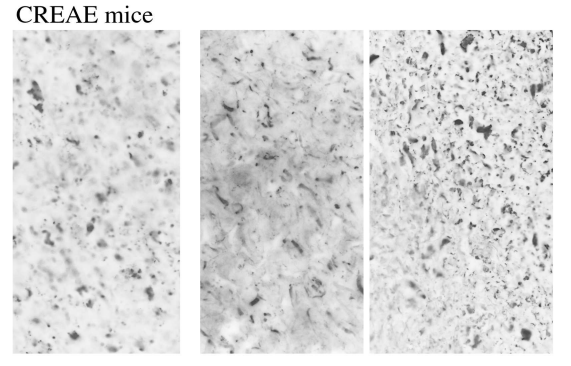

(B)

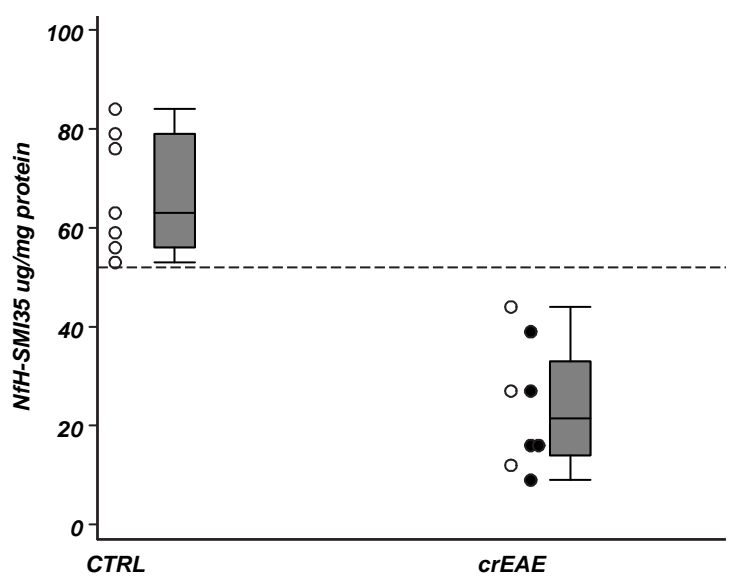

Figure 6. (A) Immunocytochemistry on longitudinal fresh frozen spinal cord sections of 3 control and 3 CREAE animals (x40). NfH staining in white matter. Axonal tracts can be followed in control but not in CREAE animals. The staining in CREAE animals is less intense and many axonal end-bulbs are seen. (B) Mice spinal cord tissue homogenates. Scatter and box-whisker plot for $\mathrm{NfH}^{S M I 35}$ (ng/mg protein). Adapted reprint with permission from [132].

cords from mice with chronic relapsing experimental autoimmune encephalomyelitis (CREAE) was demonstrated [132]. Figure $6(\mathrm{~A})$ demonstrates the near complete loss of axonal continuity, presence of axonal end-bulbs and almost abolished axonal presence in the atrophied spinal cord from CREAE mice. Analysis of this spinal cord tissue homogenate showed that levels of $\mathrm{NfH}^{S M I 35}$ corrected for the amount of total protein were significantly lower in CREAE animals compared to controls, suggestive of axonal loss (Figure 6).

\section{Nf as a surrogate marker for axonal injury in MS}

The hypothesis underlying the measurement of $\mathrm{Nf}$ as a surrogate marker for axonal damage is outlined in Figure 7. The following headings are arbitrary and only intended for didactic purposes. 

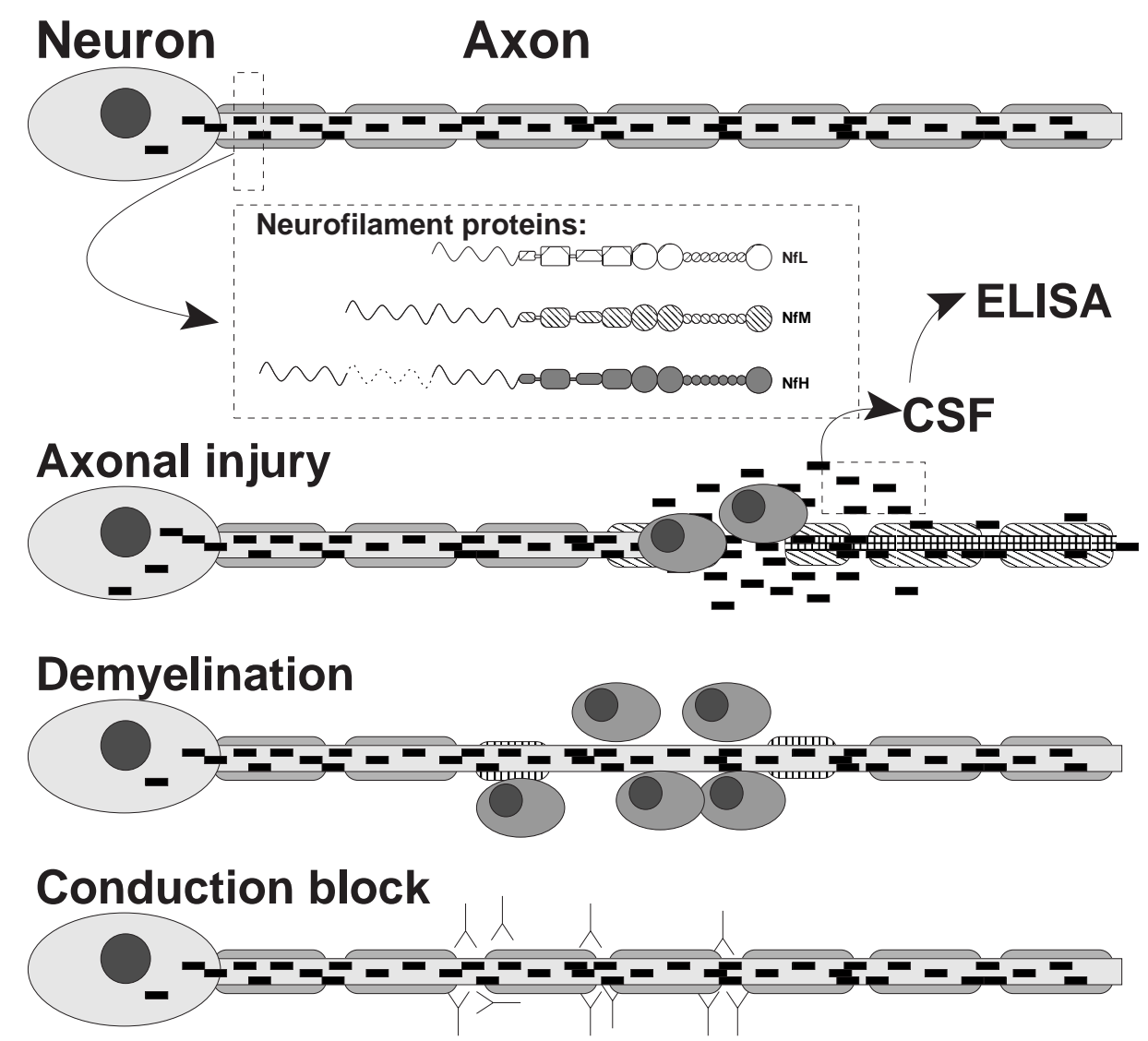

Figure 7. Neurofilaments are released into the extracellular fluid during axonal disintegration following axonal injury. Conduction block (e.g. by anti-NfH autoantibodies [77]) and demyelination are potentially reversible whilst axonal loss is not.

\subsection{CSF NfL studies}

The acyclovir trial The first paper investigating the potential of Nf as a surrogate marker for axonal injury in MS was published by Lycke and colleagues. The authors measured NfL CSF levels in patients with relapsing remitting disease participating in a trial with acyclovir [133]. These 60 patients had a mean disease duration of 5.8 years, a mean age of 33 years and an EDSS of $<4$. None of the controls (11 healthy volunteers) and $78 \%$ of the RRMS patients had detectable CSF NfL levels. Absolute values were not given, but estimating from [133, Figure 1] mean CSF NfL levels are about $990 \mathrm{ng} / \mathrm{L}$ in the first month after relapse and level at $\approx$ 200-400 ng/L three months later. 
The acute relapse study In a subsequent paper the same group obtained ethical approval to recruit $66 \mathrm{MS}$ patients and 50 healthy volunteers (blood donors) for CSF sampling [134]. 23 patients suffered from a relapse (RRMS-rel) in the 3 months prior to sampling, 18 were in remission (RRMS-rem) and 25 had SPMS. The SPMS patients were older (mean 47.7 years) than the RRMS-rel (32.4), RRMSrem (47.7) and controls (35.4). CSF NfL was determined using the same ELISA method as in 1998 [71], the only difference being that non-detectable values were substituted by $125 \mathrm{ng} / \mathrm{L}$ (the assay's sensitivity) [134]. CSF NfL levels were detectable in $8 \%$ of the controls, $48 \%$ of SPMS, $44 \%$ of RRMS-rem and $91 \%$ of RRMS-rel. Absolute values for the subgroups were not given, but estimating from [134, Figure 1] median levels for SPMS are $\approx 0(0-625) \mathrm{ng} / \mathrm{L}, \mathrm{RRMS}-\mathrm{rem} \approx$ $(0$ - 750) $\mathrm{ng} / \mathrm{L}$ and RRMS-rel $\approx(0-4,875) \mathrm{ng} / \mathrm{L}$. Of note is that in one subgroup $(\mathrm{n}=13)$ of the RRMS-rel patients follow-up CSF was available. Median CSF NfL levels were 1,877 ng/L (median of 16 days post-relapse), 2,699 ng/L (34 days) and 2,017 (105 days).

The MS siblings study The retrospective study aimed to investigate whether individuals with MS immunopathic trait showed early biochemical signs of early involvement of axons [135]. A total of 47 MS patients, 47 siblings (9 with MS trait) and 50 healthy controls (presumably the same as in [134]) were included. The mean age of the MS patients (44 years) or their siblings (44-45 years) was significantly higher than in the controls (33 years). MS patients had significantly higher CSF NfL levels (mean \pm SD $258.7 \pm 186.7 \mathrm{ng} / \mathrm{L})$ than either their siblings $(140.8 \pm 49.0 \mathrm{ng} / \mathrm{L})$ or the healthy controls $(128.3 \pm 15.8 \mathrm{ng} / \mathrm{L})$. The authors elegantly applied Fisher's permutation test for statistical analysis.

The new NfL ELISA Using a new ELISA method Rosengren and colleagues found CSF NfL levels above cutoff (100 ng/L determined as mean +3 SEM of the control group) in $2 / 11$ (18\%) healthy volunteers (mean \pm SEM $31 \pm 23 \mathrm{ng} / \mathrm{L}$ ) and 4/5 $(80 \%)$ of RRMS patients $(2,500 \pm 1,500 \mathrm{ng} / \mathrm{L})$ [73].

The dot-blot study Another group investigated NfL levels using a dot-blot immunoassay [70]. Sixteen patients with RRMS, 13 with SP MS and 6 with PPMS have been included. The age distribution was (mean \pm SD) $32.6 \pm 5.3,45.3 \pm 4.2$ and $41.2 \pm 7.4$ years, respectively. The control group consisted of 11 "healthy" individuals (8 spinal anaesthesia during labour and 3 with non-specific headache or neurotic syndromes, mean age $22.5 \pm 3.2$ years). Absolute values were not given but approximating [70, Figure 4] 24/35 (69\%) of the MS patients had values above cutoff $(\approx$ $145 \mathrm{CSF}$ NfL units/mg protein). The mean value for the controls was $\approx 100 \mathrm{NfL}$ units/mg protein, for RRMS $\approx 170 \mathrm{NfL}$ units/mg protein and for SP/PPMS $\approx 200$ $\mathrm{NfL}$ units/mg protein. Levels in RRMS and SP/PPMS patients were significantly higher than in the total group. 


\subsection{CSF NfH ${ }^{\text {SMI35 }}$ studies}

The NfH ELISA CSF NfH was also measured in 36 patients with laboratorysupported demyelinating disease (MS, CIS, ON) [31]. Based on a cut-off of 0.73 $\mathrm{ng} / \mathrm{mL}$ derived from 416 patients with other neurological diseases only 1/36 (3\%) had pathologically high CSF NfH levels, with the median level being 0.27 (0-0.36) $\mathrm{ng} / \mathrm{mL}$. The relapse free interval of this group was not recorded but all patients underwent diagnostic lumbar puncture following acute onset of neurological symptoms suggestive of a relapse-proximate LP.

The Amsterdam cohort - baseline The patients in the Amsterdam group had more benign MS than the above group, and were recruited following an announcement in response to an appeal in the periodical of the Dutch MS Society [76]. From 65 responders 51 patients fulfilled the diagnosis of MS according to the Paty criteria and agreed to undergo a LP. The median age was 46.3 years for all MS patients with RRMS being the youngest (40.0 years), followed by SPMS (46.2 years) and PPMS (51.0 years). The EDSS was 3.5, 1.75, 6.0, 6.0, respectively. The relapse free interval was substantially longer than in the other studies, 36.5 (all patients), 15.0 (RRMS), 77 (SPMS) months. Median CSF NfH levels were 0.05 (interquartile range $0.02-0.15) \mathrm{ng} / \mathrm{mL}$ for all MS patients, $0.07(0.02-0.15) \mathrm{ng} / \mathrm{mL}$ for RRMS, $0.04(0.02-0.17) \mathrm{ng} / \mathrm{mL}$ for SPMS and $0.09(0.02-0.13) \mathrm{ng} / \mathrm{mL}$ for PPMS patients. CSF NfL levels were non-detectable in this cohort. This might be due to the more benign disease course or to the sensitivity of the NfL ELISA used.

The Amsterdam cohort - 3-year follow-up Three year follow-up data was available from 34 of these patients, but only 29 agreed to a second LP [136]. 318 patients with non-inflammatory neurological disease were included as controls (it was not considered to be ethical to perform a lumbar puncture in healthy volunteers). The mean age was 44.0 years for $\mathrm{NfH}^{S M I 35}$ controls and 45.4 years for $\mathrm{NfH}^{\text {SMI34 }}$ controls. The age of the MS patients was 46.5 years for the entire cohort, 39.6 years for RRMS, 48.5 years for SP/PPMS patients (pooled from baseline cohort because of small sample size). The relapse-free interval for the MS patients was 14.0, 8.1, 16.0 months respectively. Baseline EDSS was 3.25, 1.5, 6.0 at baseline and 4.5, 3.0, 5.5 at 3-year follow-up, respectively. At baseline median CSF $\mathrm{NfH}^{\text {SMI35 }}$ levels were $0.078(0.08-0.61) \mathrm{ng} / \mathrm{mL}$ in all MS, $0.053(0.011-0.139)$ in RRMS and $0.095(0.025-0.163)$ in SP/PPMS patients. At 3-year follow-up median CSF NfH ${ }^{S M I 35}$ levels were $0.113(0.0-0.178) \mathrm{ng} / \mathrm{mL}$ in all MS, $0.0(0.0$ $0.12)$ in RRMS and $0.129(0.0-0.209)$ in SP/PPMS patients. An increase of CSF $\mathrm{NfH}^{\text {SMI35 }}$ levels was observed in a significantly higher proportion of SP/PPMS (59\%) compared to RRMS patients (14\%) suggestive of accumulation of axonal injury in the progressive phase of the disease. 
The higher CSF $\mathrm{NfH}^{S M I 35}$ and $\mathrm{NfH}^{\text {SMI34 }}$ levels in the control group compared to MS patients is in line with the previous finding [31] that axonal injury in MS seems not to be such a major pathology as observed in other neurological diseases. Because each group used different standards it is impossible to compare the absolute values. Even within the same group values between 2 different NfL ELISA techniques differed $[71,73]$.

\subsection{Plasma $\mathrm{NfH}^{\text {SMI35 }}$ studies}

There are only 2 studies investigating plasma $\mathrm{NfH}^{S M I 35}$ levels $[137,138]$. The results should therefore be regarded with caution until confirmed independently by other groups, particularly with regard to cell-type specificity as mentioned above.

Acute optic neuritis This prospective study aimed to investigate the relationship between loss and recovery of optic nerve function with surrogate markers for inflammation and for axonal injury in patients with acute optic neuritis [137]. The median plasma levels of $\mathrm{NfH}^{S M I 35}$ were significantly higher in the $\mathrm{ON}$ patients 170 (70-330) $\mathrm{pg} / \mathrm{mL}$ compared to the controls $5(0-94) \mathrm{pg} / \mathrm{mL}$. In total $50 \%$ of ON patients had plasma $\mathrm{NfH}^{S M I 35}$ levels above cut-off (top value of controls). Plasma $\mathrm{NfH}^{\text {SMI35 }}$ levels were also higher in those $36 \%$ of patients with poor recovery of visual function $(250 \mathrm{pg} / \mathrm{mL})$ when compared to those with good recovery $(9 \mathrm{pg} / \mathrm{mL})$.

The Toulouse cohort This observational study included 30 MS patients with RRMS treated with interferon $\beta$ and aimed to investigate whether treatment response could be related retrospectively to axonal and inflammatory pathology as measured by surrogate markers [138]. There were 11 responders to treatment and 19 non-responders. Median plasma $\mathrm{NfH}^{\text {SMI35 }}$ levels were significantly higher in the responders $300(0.1-2,400) \mathrm{pg} / \mathrm{mL}$ and non-responders $500(0.1-2,200) \mathrm{pg} / \mathrm{ml}$ if compared to healthy controls $4.5(0-31) \mathrm{pg} / \mathrm{mL}$. This result remained significant on a categorical level where $58 \%$ of the responder and $72 \%$ of the non-responder had levels above cut-off (top value of controls).

\subsection{Correlation with disability scales}

A weak correlation between CSF NfL and the EDSS was observed in the "acyclovir trial" at baseline (Spearman's $\mathrm{R}=0.27, \mathrm{p}<0.05)$ and after 2 years $(\mathrm{R}=0.34, \mathrm{p}<0.01)$ but the graphs displaying this correlation were not presented [133] and no such correlations were found in the "acute-relapse study" [134]. 
The "dot-blot study" revealed a correlation of CSF NfL with the EDSS (Pearson's $\mathrm{R}=0.41, \mathrm{p}<0.05)$ if only those patients with progressive disease (SP/PPMS) were subjected to analysis [70]. The graphs displaying this correlation were not shown and one might argue that the significance of this correlation would be lost after Bonferroni correction for multiple comparisons.

The "Amsterdam 3-year follow-up study" revealed a correlation between CSF

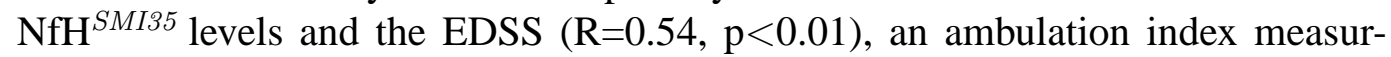
ing gait $(\mathrm{R}=0.42, \mathrm{p}<0.05)$ and the 9 hole $\mathrm{PEG}$ test $(\mathrm{R}=0.59, \mathrm{p}<0.01)$. However, no such correlations were found at baseline in either the original cohort $(n=54)$ [76] or the baseline values of the subgroup with 3-year follow-up data $(n=39$, unpublished data).

The "acute optic neuritis study" demonstrated a negative correlation between $\mathrm{NfH}^{\text {SMI35 }}$ and visual acuity (VA) at the time of first presentation $(\mathrm{R}=-0.67, \mathrm{p}=0.01)$ [137].

Although it might be desirable from a publishing point of view to find a correlation between a clinical scale and CSF Nf levels, one needs to remember that not each lesion in the CNS translates into deficit on a clinical scale. Additionally some clinical deficit might be caused by demyelination or conduction block alone. From a clinical point of view it would be more important to identify those patients who are "at risk" of developing progressive disease due to axonal loss with subsequent progression of disability. From a trial point of view rigorous inclusion criteria (i.e. patients with early evidence for axonal degeneration) would help to avoid the potential for selection bias in treatment trials for neuroprotective drugs by cohort contamination with patients showing evidence for inflammation only (prone to bias by regression to the mean).

Nf auto-antibody levels The work on anti-NfL and anti-NfH autoantibodies has largely been done by E Silber using bovine NfL and NfH in an ELISA setup $[75,76]$. He discovered a 2-fold higher mean anti NfL index in PPMS (466) and SPMS (499) patients compared to RR MS patients (208) or inflammatory controls (169) [75]. For the anti NfH index the differences were less marked RRMS (381), PPMS (455), SPMS (501) and inflammatory controls (155). The anti-NfL index correlated with disease duration (Spearman's $\mathrm{R}=0.42, \mathrm{p}<0.0001$ ) and the EDSS $(\mathrm{R}=0.54, \mathrm{p}<0.0001)$. Although these correlations are moderate at best, the figures show that the findings were not based on outliers.

Applying his technique to the Amsterdam cohort at baseline we found a correlation of the anti-NfL index with MRI measures such as the PF (Spearman's R=$0.51, \mathrm{p}<0.001)$, the $\mathrm{T} 1$ lesion load $(\mathrm{R}=0.37, \mathrm{p}<0.05)$, the $\mathrm{T} 2$ lesion load $(\mathrm{R}=0.41$, $\mathrm{p}<0.05)$ and the $\mathrm{VF}(\mathrm{R}=0.37, \mathrm{p}<0.05)$. For the anti-NfH index there was only a correlation with the PF $(\mathrm{R}=-0.39, \mathrm{p}<0.05)$. These correlations were mainly based on the results for the RRMS subgroup were the anti-NfL index correlated with the 
PF, VF and T1LL $(\mathrm{R}=-0.56, \mathrm{p}<0.05 ; \mathrm{R}=0.72, \mathrm{p}<0.01$ and $\mathrm{R}=0.61, \mathrm{p}<0.05$, respectively). However, the results for the T1 \& T2 lesion load and VF were partly based on 2-3 outliers [76]. With one exception (a weak correlation with the PF in the whole cohort, $\mathrm{R}=-0.39, \mathrm{p}<0.05$ ) no such correlations were found for the anti-NfH index [76].

5.4.0.1 Acknowledgements I am grateful to Dr Geoffrey Keir and Professor Edward Thompson for comments on the manuscript.

5.4.0.2 Post scriptum Since submission of this review another study on CSF NfH was published: Lim ET et al. "Cerebrospinal fluid levels of brain specific proteins in optic neuritis", Mult Scler 2004;10:261-265.

\section{References}

[1] E Fuchs and DW Cleveland. A structural scaffolding of intermediate filaments in health and disease. Science, 279:514-519, 1998.

[2] GM Cooper, editor. The Cell - A Molecular Approach. Sunderland (MA): Sinauer Associates, Inc., 2000.

[3] MK Lee and DW Cleveland. Neuronal intermediate filaments. Ann Rev Neurosci, 19:187-217, 1996.

[4] JF Lees, PS Shneidman, SF Skuntz, MJ Carden, and RA Lazzarini. The structure and organization of the human heavy neurofilament subunit (NFH) and the gene encoding it. EMBO1988, 7:1947-1955, 1988.

[5] N Geisler, E Kaufmann, S Fischer, U Plessmann, and K Weber. Neurofilament architecture combines structural principles of intermediate filaments with carboxy-terminal extensions increasing in size between triplet proteins. EMBO J, 2:1295-1502, 1983.

[6] RK Sihag and RA Nixon. In vivo phosphorylation of distinct domains of the 70- kilodalton neurofilament subunit involves different protein- kinases. $J$ Biol Chem, 264:457-464, 1989.

[7] SR Gill, PC Wong, MJ Monteiro, and DW Cleveland. Assembly properties of dominant and recessive mutations in the small mouse neurofilament (NfL) subunit. J Cell Biology, 111:2005-2019, 1990.

[8] S Hisanaga, Y Gonda, M Inagaki, A Ikai, and N Hirokawa. Effects of phosphorylation of the neurofilament L-protein on filamentous structures. Cell Regulation, 1:237-248, 1990.

[9] Y Nakamura, M Takeda, KJ Angelides, T Tanaka, K Tada, and T Nishimura. Effect of phosphorylation on $68 \mathrm{kda}$ neurofilament subunit protein assembly by the cyclic-amp dependent protein-kinase in vitro. Biochem Biophys Res Comm, 169:744-750, 1990. 
[10] RK Liem and SB Hutchison. Purification of individual components of the neurofilament triplet: filament assembly from the 70 000-dalton subunit. Biochemistry, 21(13):3221-3206, June 1982.

[11] N Geisler and K Weber. Self assembly in vitro of the 68000 molecular weight component of the mammalian neurofilament triplet proteins into intermediate-sized filaments. J Mol Biol, 151:565-571, 1981.

[12] MK Lee, Z Xu, PC Wong, and DW Cleveland. Neurofilaments are obligate heteropolymers in vivo. J Cell Biol, 122(6):1337-1350, September 1993.

[13] S Heins, PC Wong, et al. The rod domain of NF-1 determines neurofilament architecture, whereas the end domains specify filament assembly and network formation. J Cell Biol, 123(6 Pt 1):1517-1533, December 1993.

[14] MD Nguyen, RC Lariviere, and JP Julien. Deregulation of Cdk5 in a mouse model of ALS: toxicity alleviated by perikaryal neurofilament inclusions. Neuron, 30:135-47, 2001.

[15] SM Dewaegh, VMY Lee, and ST Brady. Local modulation of neurofilament phosphorylation, axonal caliber, and slow axonal-transport by myelinating Schwann-cells. Cell, 68:451-463, 1992.

[16] P Grant and HC Pant. Neurofilament protein synthesis and phosphorylation. J Neurocytol, 29(11-12):843-872, Nov-Dec 2000.

[17] CC Miller, S Ackerley, J Brownlees, AJ Grierson, NJ Jacobsen, and P Thornhill. Axonal transport of neurofilaments in normal and disease states. Cell Mol Life Sci, 59:323-330, 2002.

[18] MJ Strong, WL Strong, H Jaffe, B Traggert, MM Sopper, and HC Pant. Phosphorylation state of the native high-molecular-weight neurofilament subunit protein from cervical spinal cord in sporadic amyotrophic lateral sclerosis. J Neurochem, 76:1315-1325, 2001.

[19] JC Betts, WP Blackstock, MA Ward, and BH Anderton. Identification of phosphorylation sites on neurofilament proteins by nanoelectrospray mass spectrometry. J Biol Chem, 272:12922-12927, 1997.

[20] RJ Guan, BS Khatra, and JA Cohlberg. Phosphorylation of bovine neurofilament proteins by protein-kinase fa (glycogen-synthase kinase-3). J Biol Chem, 266:8262-8267, 1991.

[21] S Guidato, LH Tsai, J Woodgett, and CC Miller. Differential cellular phosphorylation of neurofilament heavy side-arms by glycogen synthase kinase-3 and cyclin-dependent kinase-5. J Neurochem, 66:1698-2306, 1996.

[22] HM Roder and VM Ingram. 2 novel kinases phosphorylate-tau and the KSP site of heavy neurofilament subunits in high stoichiometric ratios. J Neurosci, 11:3325-3343, 1991.

[23] HM Roder, FJ Hoffman, and W Schroder. Phosphatase resistance of erk2 brain kinase PK40(erk2). J Neurochem, 64:2203-2212, 1995.

[24] J Lew, RJ Winkfein, HK Paudel, and JH Wang. Brain proline-directed protein-kinase is a neurofilament kinase which displays high sequence homology to P34(cdc2). J Biol Chem, 267:25922-25926, 1992.

[25] KT Shetty, WT Link, and HC Pant. cdc2-like kinase from rat spinal-cord specifically phosphorylates KSPXK motifs in neurofilament proteins - iso- 
lation and characterization. Proc Nat Acad Sci USA, 90:6844-6848, 1993.

[26] RK Sihag and RA Nixon. Phosphorylation of the amino-terminal head domain of the middle molecular mass $145-\mathrm{kDa}$ subunit of neurofilaments evidence for regulation by 2 nd messenger-dependent protein-kinases. $J$ Biol Chem, 265:4166-4171, 1990.

[27] RK Sihag and RA Nixon. Identification of Ser-55 as a major protein kinasea phosphorylation site on the $70-\mathrm{kDa}$ subunit of neurofilaments - early turnover during axonal-transport. J Biol Chem, 266:18861-18867, 1991.

[28] DL Dong, ZS Xu, GW Hart, and DW Cleveland. Cytoplasmic O-GlcNAc modification of the head domain and the KSP repeat motif of the neurofilament protein neurofilament-H. J Biol Chem, 271:20845-20852, 1996.

[29] DL Dong, ZS Xu, et al. Glycosylation of mammalian neurofilaments. Localization of multiple O-linked $\mathrm{N}$-acetylglucosamine moieties on neurofilament polypeptides L and M. J Biol Chem, 268:16679-16687, 1993.

[30] NH Sternberger, LA Sternberger, and J Ulrich. Aberrant neurofilament phosphorylation in Alzheimer disease. Proc Natl Acad Sci USA, 82:4274-4276, 1985.

[31] A Petzold, G Keir, AJE Green, et al. A specific ELISA for measuring neurofilament heavy chain phosphoforms. J Immunol Methods, 278:179-190, 2003.

[32] RJ Lasek and MM Black, editors. Intrinsic determinants of neuronal form and function, volume 37 of Neurology and Neurobiology, 41 East 11th Street, New York, NY 10003, 1988. Alan R Liss. Proceedings of a Meeting on Intrinsic Determinants of Neuronal Form and Function held at the Bio-architectonics Center, School of Medicine, Case Western Reserve University, Cleveland, Ohio, May 12-14, 1986.

[33] RA Nixon. The regulation of neurofilament protein dynamics by phosphorylation - clues to neurofibrillary pathobiology. Brain Pathology, 3:29-38, 1993.

[34] JW Griffin, EB George, ST Hsieh, and JD Glass. The axon: structure, function and pathophysiology, chapter Axonal degeneration and disorders of the axonal cytoskeleton, pages 375-390. In Waxman et al. [35], 1995.

[35] SG Waxman, JD Kocsis, and PK Stys, editors. The axon: structure, function and pathophysiology. Oxford University Press, New York, Oxford, 1995.

[36] PN Hoffman, DW Cleveland, JW Griffin, et al. Neurofilament gene expression: a major determinant of axonal caliber. Proc Natl Acad Sci USA, 84:3472-3476, 1987.

[37] MV Rao, MK Houseweart, TL Williamson, TO Crawford, J Folmer, and DW Cleveland. Neurofilament-dependent radial growth of motor axons and axonal organization of neurofilaments does not require the neurofilament heavy subunit (NF-H) or its phosphorylation. J Cell Biol, 143:171-81, 1998.

[38] GA Elder, VL Jr Friedrich, P Bosco, C Kang, A Gourov, PH Tu, VM Lee, and RA Lazzarini. Absence of the mid-sized neurofilament subunit decreases axonal calibers, levels of light neurofilament (NF-L), and neurofilament content. J Cell Biol, 141:727-739, 1998. 
[39] GA Elder, Jr Friedrich VL, A Margita, and RA Lazzarini. Age-related atrophy of motor axons in mice deficient in the mid-sized neurofilament subunit. J Cell Biol, 146:181-92, 1999.

[40] GA Elder, Jr Friedrich VL, D Pereira, et al. Mice with disrupted midsized and heavy neurofilament genes lack axonal neurofilaments but have unaltered numbers of axonal microtubules. J Neurosci Res, 57:23-32, 1999.

[41] H Jacomy, QZ Zhu, S Couillard-Després, JM Beaulieu, and JP Julien. Disruption of type IV intermediate filament network in mice lacking the neurofilament medium and heavy subunits. J Neurochem, 73:972-984, 1999.

[42] TL Williamson, LI Bruijn, et al. Absence of neurofilaments reduces the selective vulnerability of motor neurons and slows disease caused by amyotrophic lateral sclerosis-linked superoxide dismutase 1 mutant. Proc Natl Acad Sci USA, 95:9631-9636, 1998.

[43] JP Julien. Neurofilament functions in health and disease. Curr Opin Neurobiol, 9:554-560, 1999.

[44] Q Zhu, M Lindenbaum, F Levavasseur, H Jacomy, and JP Julien. Disruption of the NF-H gene increases axonal microtubule content and velocity of neurofilament transport: relief of axonopathy resulting from the toxin beta,beta'iminodipropionitrile. J Cell Biol, 143:183-193, 1998.

[45] S Couillard-Despres, Q Zhu, PC Wong, DL Price, DW Cleveland, and JP Julien. Protective effect of neurofilament heavy gene overexpression in motor neuron disease induced by mutant superoxide dismutase. Proc Natl Acad Sci USA, 95:9626-9630, 1998.

[46] JP Gou, T Gotow, PA Janmey, and JF Leterrier. Regulation of neurofilament interactions in vitro by natural and synthetic polypeptides sharing Lys-SerPro sequences with the heavy neurofilament subunit NF-h: neurofilament crossbridging by antiparallel sidearm overlapping. Med Biol Eng Comput, 36(3):371-387, May 1998.

[47] S Hisanaga, S Yasugawa, et al. Dephosphorylation of microtubule-binding sites at the neurofilament-H tail domain by alkaline, acid, and protein phosphatases. J Biochem, 113(6):705-709, June 1993.

[48] H Miyasaka, S Okabe, et al. Interaction of the tail domain of high molecular weight subunits of neurofilaments with the $\mathrm{COOH}$-terminal region of tubulin and its regulation by tau protein kinase II. J Biol Chem, 268(30):2269523302, October 1993.

[49] RC Lariviere and JP Julien. Functions of intermediate filaments in neuronal development and disease. J Neurobiol, 58:131-48, 2004.

[50] S Hisanaga and N Hirokawa. Molecular architecture of the neurofilament. II. Reassembly process of neurofilament L protein in vitro. J Mol Biol, 211(4):871-882, February 1990.

[51] S Hisanaga, Y Matsuoka, et al. Phosphorylation of native and reassembled neurofilaments composed of NF-L, NF-M, and NF-H by the catalytic subunit of cAMP-dependent protein kinase. Mol Biol Cell, 5(2):161-72, February 1994.

[52] S Roy, P Coffee, G Smith, et al. Neurofilaments are transported rapidly but 
intermittently in axons: implications for slow axonal transport. J Neurosci, 20:6849-6861, 2000.

[53] Z Xu and VW Tung. Overexpression of neurofilament subunit $\mathrm{M}$ accelerates axonal transport of neurofilaments. Brain Res, 866:326-332, 2000.

[54] Z Xu and VW Tung. Temporal and spatial variations in slow axonal transport velocity along peripheral motoneuron axons. Neuroscience, 102:193-200, 2001.

[55] S Acerklay, AJ Grierson, J Brownless, et al. Glutamate slows axonal transport of neurofilaments in transfected neurons. J Cell Biol, 150:165-176, 2000.

[56] PN Hoffman and RJ Lasek. The slow component of axonal transport. Identification of major structural polypeptides of the axon and their generality among mammalian neurons. J Cell Biol, pages 351-366, 1975.

[57] A Al-Chalabi and CC Miller. Neurofilaments and neurological disease. Bioessays, 25:346-355, 2003.

[58] DF Watson, JW Griffin, KP Fittro, and PN Hoffman. Phosphorylationdependent immunoreactivity of neurofilaments increases during axonal maturation and beta,beta-iminodipropionitrile intoxication. J Neurochem, 53:1818-1829, 1989.

[59] DF Watson, KP Fittro, PN Hoffman, and JW Griffin. Phosphorylationrelated immunoreactivity and the rate of transport of neurofilaments in chronic 2,5-hexanedione intoxication. Brain Res, 539:103-9, 1991.

[60] RA Nixon, PA Paskevich, RK Sihag, and CY Thayer. Phosphorylation on carboxyl-terminus domains of neurofilament proteins in retinal ganglion-cell neurons in- vivo - influences on regional neurofilament accumulation, interneurofilament spacing, and axon caliber. J Cell Biology, 126:1031-1046, 1994.

[61] JT Yabe, A Pimenta, and TB Shea. Kinesin-mediated transport of neurofilament protein oligomers in growing axons. J Cell Sci, 112:3799-4514, 1999.

[62] S Ackerley, AJ Grierson, et al. Glutamate slows axonal transport of neurofilaments in transfected neurons. J Cell Biol, 150:165-76, 2000.

[63] WW Schlaepfer, C Lee, VMY Lee, and UJP Zimmerman. An immunoblot study of neurofilament degradation in situ and during calcium-activated proteolysis. J Neurochem, 44:502-509, 1985.

[64] S Wang, GJ Lees, LE Rosengren, JE Karlsson, A Hamberger, and KG Haglid. Proteolysis of filament proteins in glial and neuronal cells after in vivo stimulation of hippocampal NMDA receptors. Neurochem Res, 17:1005-1009, 1992.

[65] WL Maxwell, JT Povlishock, and DL Graham. A mechanistic analysis of nondisruptive axonal injury: A review. J Neurotrauma, 14:419-440, 1997.

[66] ME Goldstein, NH Sternberger, and LA Sternberger. Phosphorylation protects neurofilaments against proteolysis. J Neuroimmunol, 14:149-160, 1987.

[67] LA Sternberger and NH Sternberger. Monoclonal antibodies distinguish 
phosphorylated and non-phosphorylated forms of neurofilaments in situ. Proc Natl Acad Sci USA, 82:6126-6130, 1983.

[68] HC Pant. Dephosphorylation of neurofilament proteins enhances their susceptibility to degradation by calpain. Biochem J, 256:665-608, 1988.

[69] ME Goldstein, LA Sternberger, and NH Sternberger. Varying degrees of phosphorylation determine microheterogeneity of the heavy neurofilament poypeptide (Nf-H). J Neuroimmunol, 14:135-148, 1987.

[70] YK Semra, OA Seidi, and MK Sharief. Heightened intrathecal release of axonal cytoskeletal proteins in multiple sclerosis is associated with progressive disease and clinical disability. J Neuroimmunol, 122:132-109, 2002.

[71] LE Rosengren, JE Karlsson, JO Karlsson, LI Persson, and C Wikkelso. Patients with amyotrophic lateral sclerosis and other neurodegenerative diseases have increased levels of neurofilament protein in CSF. J Neurochem, 67:2013-2018, 1996.

[72] R Hashimoto, Y Nakamura, T Ichiro, et al. Quantitative analysis of neurofilament proteins in Alzheimer's brain by enzyme linked immunosorbent assay system. Psychiat and Clin Neurosci, 53:587-591, 1999.

[73] N Norgren, L Rosengren, and T Stigbrand. Elevated neurofilament levels in neurological diseases. Brain Res, 987(1):25-31, October 2003.

[74] R Graf and P Friedl. Charge-coupled device camera-based detection of fluorescence-labeled proteins immobilized on nitrocellulose membranes. Electrophoresis, 22(5):890-805, March 2001.

[75] E Silber, YK Semra, NA Gregson, and MK Sharief. Patients with progressive multiple sclerosis have elevated antibodies to neurofilament subunit. Neurology, 58(9):1372-1381, May 2002.

[76] MJ Eikelenboom, A Petzold, RH Lazeron, et al. Multiple sclerosis: Neurofilament light chain antibodies are correlated to cerebral atrophy. Neurology, 60:219-223, 2003.

[77] Jr. Stubbs EB, MW Lawlor, et al. Anti-neurofilament antibodies in neuropathy with monoclonal gammopathy of undetermined significance produce experimental motor nerve conduction block. Acta Neuropathol, 105:109-16, 2003.

[78] AM Salih, NB Nixon, PT Dawes, and DL Mattey. Prevalence of antibodies to neurofilament polypeptides in patients with rheumatoid arthritis complicated by peripheral neuropathy. Clin Exp Rheumatol, 16:689-694, 1998.

[79] SA Sadiq, LH van den Berg, et al. Human monoclonal antineurofilament antibody cross-reacts with a neuronal surface protein. J Neurosci Res, 29:319325, 1991.

[80] DN Herrmann and JW Griffin. Intermediate filaments. A common thread in neuromuscular disorders. Neurology, 58:1141-1143, 2002.

[81] GA Rouleau, AW Clark, K Rooke, A Pramatarova, A Krizus, O Suchowersky, JP Julien, and D Figlewicz. SOD1 mutation is associated with accumulation of neurofilaments in amyotrophic lateral sclerosis. Ann Neurol, 39:128-131, 1996.

[82] Z Xu, LC Cork, JW Griffin, and DW Cleveland. Increased expression of 
neurofilament subunit NF-L produces morphological alterations that resemble the pathology of human motor neuron disease. Cell, 73:23-33, 1993.

[83] Ak Ashbury, MK Gale, SC Cox, JR Baringer, and BO Berg. Giant axonal neuropathy: a unique case with segmental neurofilamentous masses. Acta Neuropathol, 20:237-247, 1972.

[84] BD Trapp, JP Peterson, et al. Axonal transection in the lesions of multiple sclerosis. N Eng J Med, 338:278-285, 1998.

[85] L Bö. Grey matter pathology in early MS. In DH Miller, M Filipi, and AJ Thompson, editors, MAGNIMS Clinically Isolated Syndrome Workshop, The National Hospital for Neurology \& Neurosurgery, Queen Square, London, WC1N 3BG, 22.-23. Jan 2004. MS NMR Research Unit, Department of Neuroinflammation.

[86] H Zhang, NH Sternberger, LJ Rubinstein, et al. Abnormal processing of multiple proteins in Alzheimer disease. Proc Natl Acad Sci USA, 86:80458049, 1989.

[87] JS Su, BJ Cummings, and CW Cotman. Plaque biosynthesis in brain aging and Alzheimer's disease: I Progressive changes in phosphorylation states of paired helical filaments and neurofilaments. Brain Res, 739:79, 1996.

[88] JH Su, BJ Cummings, and CW Cotman. Plaque biosynthesis in aging brain and Alzheimer's disease: II Progressive transformation and developmental sequence of dystrophic neurites. Acta Neuropath, 96:463, 1998.

[89] JH Morrison, DA Lewis, MJ Campbell, GW Huntley, DL Benson, and C Bouras. A monoclonal antibody to non-phosphorylated neurofilament protein marks the vulnerable cortical neurons in Alzheimer's disease. Brain Res, 416:331-336, 1987.

[90] PR Hof, K Cox, and JH Morrison. Quantitative analysis of a vulnerable subset of pyramidal neurons in Alzheimer's disease: I superior frontal and inferior temporal cortex. J Comp Neurol, 301:44-54, 1990.

[91] F Gottron, D Turetsky, and D Choi. SMI-32 antibody against nonphosphorylated neurofilaments identifies a subpopulation of cultured cortical neurons hypersensitive to kainate toxicity. Neurosci Lett, 194:1, 1995.

[92] DG Munoz, C Greene, DP Perl, and DJ Selkoe. Accumulation of Phosphorylated Neurofilaments in anterior horn motoneurons of amyotrophic lateral sclerosis patients. J Neuropathol Exp Neurol, 47:9-18, 1988.

[93] N Vartiainen, T Tikka, R Keinanen, PH Chan, and J Koistinaho. Glutamatergic receptors regulate expression, phosphorylation and accumulation of neurofilaments in spinal cord neurons. Neuroscience, 93:1123-1133, 1999.

[94] TM Tikka and JE Koistinaho. Minocycline provides neuroprotection against $\mathrm{N}$-methyl-D-aspartate neurotoxicity by inhibiting microglia. J Immunol, 166:7527-7533, 2001.

[95] TM Tikka, NE Vartiainen, G Goldsteins, SS Oja, PM Andersen, SL Marklund, and J Koistinaho. Minocycline prevents neurotoxicity induced by cerebrospinal fluid from patients with motor neurone disease. Brain, 125:722731, 2002.

[96] JP Julien. Amyotrophic lateral sclerosis unfolding the toxicity of the mis- 
folded. Cell, 104:581-591, 2001.

[97] JP Julien. Neurofilament functions in health and disease. Curr Opin Neurobiol, 9:554-560, 1999.

[98] JP Julien. Neurofilaments and motor neuron disease. Trends in Cell Biology, 7:243-243, 1997.

[99] MJ Strong. The basic aspects of therapeutics in amyotrophic lateral sclerosis. Pharmacology \& Therapeutics, 98:379-414, 2003.

[100] JC Hedreen and VE Kolliatsos. Phosphorylated neurofilaments in neuronal perikarya and dendrites in human brain following axonal damage. $\mathrm{J} \mathrm{Neu-}$ ropath Exp Neurol, 53:663, 1994.

[101] A Petzold, K Rejdak, A Belli, et al. Axonal pathology in subarachnoid and intracerebral hemorrhage. J Neurotrauma.

[102] K Kashiwagi, B Ou, S Nakamura, et al. Increase in dephosphorylation of the heavy neurofilament subunit in the monkey chronic glaucoma model. Invest Ophthalmol Vis Sci, 44(1):154-109, January 2003.

[103] MM Reilly. Classification of the hereditary motor and sensory neuropathies. Curr Opin Neurol, 13:561-504, 2000.

[104] PF Chance and M Reilly. Inherited neuropathies. Curr Opin Neurol, 7:372380, 1994.

[105] IV Mersiyanova, AV Perepelov, et al. A new variant of CharcotMarie-Tooth disease type 2 is probably the result of a mutation in the neurofilament-light gene. Am J Hum Genet, 67:37-46, 2000.

[106] P De Jonghe, I Mersivanova, E Nelis, J Del Favero, JJ Martin, C Van Broeckhoven, O Evgrafov, and V Timmerman. Further evidence that neurofilament light chain gene mutations can cause Charcot-Marie-Tooth disease type 2E. Ann Neurol, 49:245-249, 2001.

[107] JR Lupski. Axonal charcot-marie-tooth disease and the neurofilament light gene (NF-L). Am J Hum Genet, 67:8-10, 2000.

[108] S Zuchner, M Vorgerd, E Sindern, and JM Schroder. The novel neurofilament light (nefl) mutation glu397lys is associated with a clinically and morphologically heterogeneous type of charcot-marie-tooth neuropathy. Neuromuscul Disord, 14:147-57, 2004.

[109] DM Georgiou, J Zidar, M Korosec, et al. A novel nf-1 mutation pro22ser is associated with cmt 2 in a large slovenian family. Neurogenetics, 4:93-6, 2002.

[110] MK Lee, JR Marszalek, and Cleveland DW. A mutant neurofilament subunit causes massive, selective motor neuron death: implications for the pathogenesis of human motor neuron disease. Neuron, 13:975-988, 1994.

[111] C Lavedan, S Buchholtz, et al. A mutation in the human neurofilament M gene in Parkinson's disease that suggests a role for the cytoskeleton in neuronal degeneration. Neurosci Lett, 322(1):57-61, March 2002.

[112] RE Schmidt, LN Beaudet, SB Plurad, and DA Dorsey. Axonal cytoskeletal pathology in aged and diabetic human sympathetic autonomic ganglia. Brain Res, 769(2):375-383, September 1997.

[113] P Fernyhough, A Gallagher, SA Averill, JV Priestley, L Hounsom, J Patel, 
and DR Tomlinson. Aberrant neurofilament phosphorylation in sensory neurons of rats with diabetic neuropathy. Diabetes, 48:881-889, 1999.

[114] P Bomont, L Cavalier, F Blondeau, C Ben Hamida, S Belal, M Tazir, E Demir, H Topaloglu, R Korinthenberg, B Tuysuz, P Landrieu, F Hentati, and $\mathrm{M}$ Koenig. The gene encoding gigaxonin, a new member of the cytoskeletal BTB/kelch repeat family, is mutated in giant axonal neuropathy. Nat Genet, 26:370-374, 2000.

[115] M Ferrer-Alcon, JA Garcia-Sevilla, et al. Regulation of nonphosphorylated and phosphorylated forms of neurofilament proteins in the prefrontal cortex of human opioid addicts. J Neurosci Res, 61:338-349, 2000.

[116] PE Jaquet, M Ferrer-Alcon, et al. Acute and chronic effects of morphine and naloxone on the phosphorylation of neurofilament-H proteins in the rat brain. Neurosci Lett, 304:37-40, 2001.

[117] LA Sternberger, LW Harwell, and NH Sternberger. Neurotype: Regional individuality in rat brain detected by immunocytochemistry with monoclonal antibodies. Proc Natl Acad Sci USA, 79:1326-1330, 1982.

[118] LA Sternberger, editor. Immunocytochemistry. John Wiley, New York, third edition, 1986.

[119] V Manetto, NH Sternberger, G Perry, et al. Phosphorylation of neurofilaments is altered in amyotrophic lateral sclerosis. J Neuropathol Exp Neurol, 47:642-653, 1988.

[120] LC Cork, NH Sternberger, LA Sternberger, MF Casanova, RG Struble, and DL Price. Phosphorylated neurofilament antigens in neurofibrillary tangles in Alzheimer's disease. J Neuropathol Exp Neurol, 45:56-64, 1986.

[121] BH Anderton, D Breinburg, MJ Downes, PJ Green, BE Tomlinson, J Ulrich, JN Wood, and J Kahn. Monoclonal antibodies show that neurofibrillary tangles and neurofilaments share antigenic determinants. Nature, 298:84-6, 1982.

[122] MC Haugh, A Probst, J Ulrich, J Kahn, and BH Anderton. Alzheimer neurofibrillary tangles contain phosphorylated and hidden neurofilament epitopes. J Neurol Neurosurg Psychiatry, 49:1213-1220, 1986.

[123] TH Moss and SJ Lewkowicz. The axon reaction in motor and sensory neurones of mice studied by a monoclonal antibody marker of neurofilament protein. J Neurol Sci, 60:267-280, 1983.

[124] Y Nakazato, A Sasaki, J Hirato, and Y Ishida. Monoclonal antibodies which recognize phosphorylated and nonphosphorylated epitopes of neurofilament protein. Biomed REs, 8:369-376, 1987.

[125] Y Nakazato, J Hirato, Y Ishida, S Hoshi, M Hasegawa, and T Fukuda. Swollen cortical neurons in Creutzfeldt-Jakob disease contain a phosphorylated neurofilament epitope. J Neuropathol Exp Neurol, 49:197-205, 1990.

[126] CF Lippa and TW Smith. Chromatolytic neurons in Werdnig-Hoffmann disease contain phosphorylated neurofilaments. Acta Neuropathol, 77:9194, 1988.

[127] L Autilio-Gambetti, P Gambetti, and RC Crane. Biological aspects of Alzheimer's disease, chapter Paired helical filaments: relatedness to neurofil- 
aments shown by silver staining and reactivity with monoclonal antibodies, pages 117-124. Cold Spring Harbor Laboratory, New York, 1983.

[128] M Tabaton, G Perry, L Autilio-Gambetti, V Manetto, and P Gambetti. Influence of neuronal location on antigenic properties of neurofibrillary tangles. Ann Neurol, 23:604-610, 1988.

[129] JE Martin, KS Mather, M Swash, O Garofalo, GE Dale, PN Leigh, and BH Anderton. Spinal cord trauma in man: studies of phosphorylated neurofilament and ubiquitin expression. Brain, 113:1553-1562, 1990.

[130] A Murphy, KC Breen, et al. Neurofilament expression in human T lymphocytes. Immunology, 79:167-70, 1993.

[131] T Belecky-Adams, DC Wight, JJ Kopchick, and LM Parysek. Intragenic sequences are required for cell type-specific and injury-induced expression of the rat peripherin gene. J Neurosci, 13:5056-5065, 1993.

[132] A Petzold, D Baker, G Pryce, et al. Quantification of neurodegeneration by measurement of brain-specific proteins. J Neuroimmunol, 138:45-48, 2003.

[133] JN Lycke, JE Karlsson, O Andersen, and LE Rosengren. Neurofilament protein in cerebrospinal fluid: a potential marker of activity in multiple sclerosis. J Neurol Neurosurg Psychiatry, 64:402-404, 1998.

[134] C Malmestrom, S Haghighi, L Rosengren, O Andersen, and J Lycke. Neurofilament light protein and glial fibrillary acidic protein as biological markers in MS. Neurology, 61:1720-1705, 2003.

[135] S Haghighi, O Andersen, A Oden, and L Rosengren. Cerebrospinal fluid markers in MS patients and their healthy siblings. Acta Neurol Scand, 109:97-9, 2004.

[136] A Petzold, MJ Eikelenboom, G Keir, et al. Axonal damage accumulates in the progressive phase of multiple sclerosis: A 3-year follow-up study. $J$ Neurol Neurosurg Psychiatry, in print.

[137] A Petzold, K Rejdak, and GT Plant. Axonal degeneration and inflammation in acute optic neuritis. J Neurol Neurosurg Psychiatry, 75:1178-1780, 2004.

[138] A Petzold, D Brassat, P Mas, K Rejdak, G Keir, G Giovannoni, EJ Thompson, and M Clanet. Treatment response in relation to inflammatory and axonal surrogate marker in multiple sclerosis. Mult Scler, 10:281-283, 2004. 